1 TITLE; Manganese toxicity disrupts indole acetic acid homeostasis and suppresses

$2 \quad \mathrm{CO}_{2}$ assimilation reaction in rice plants

3 RUNNING TITLE; Mechanism of symplastic Mn toxicity in rice

5 AUTHORS; Daisuke Takagi ${ }^{1,2 *}, K^{1}$ eiki Ishiyama ${ }^{2}$, Mao Suganami ${ }^{2 \star}$, Tomokazu Ushijima ${ }^{1}$,

6 Takeshi Fujii', Youshi Tazoe ${ }^{2, \uparrow}$, Michio Kawasaki ${ }^{1}, K^{1}$ Noguchi ${ }^{3}$, Amane Makino $^{2}$

7 AUTHORS AFFILIATIONS;

$8{ }^{1}$ Faculty of Agriculture, Setsunan University, Hirakata, Osaka 573-0101, Japan

$9 \quad{ }^{2}$ Graduate School of Agricultural Science, Tohoku University, Sendai, Miyagi 980-8572,

10 Japan

$11{ }^{3}$ Department of Applied Life Science, School of Life Sciences, Tokyo University of

12 Pharmacy and Life Sciences, Hachioji, Tokyo, 192-0392 Japan

13 'Present address; Faculty of Agro-Food Science, Niigata Agro-Food University, Tainai,

14 Niigata, 959-2702 Japan

15 Present address; Faculty of Food and Agricultural Sciences, Fukushima University,

16 Kanayagawa, Fukushima, 960-1296, Japan

$17 \quad{ }^{*}$ Corresponding author

18 E-MAIL ADDRESSES

19 Daisuke Takagi $\quad$ (daisuke.takagi@setsunan.ac.jp); $\quad K e i k i \quad$ Ishiyama

20 (keiki.ishiyama.e5@tohoku.ac.jp); Mao Suganami (mao.suganami@agri.fukushima-u.ac.jp);

21 Tomokazu Ushijima (tomokazu.ushijima@setsunan.ac.jp); Takeshi Fujii

22 (takeshi.fujii@setsunan.ac.jp); Youshi Tazoe (yushi-tazoe@nafu.ac.jp); Michio Kawasaki

23 (michio.kawasaki@setsunan.ac.jp); Ko Noguchi (knoguchi@toyaku.ac.jp); Amane Makino

24 (amanemakino@tohoku.ac.jp);

25 Date of submission: 17 March 2021

26 Number of tables and figures: no tables and 9 figures

27 Word counts: 5739 words (excluding Materials and Methods)

28 Number of supplemental tables and figures: 2 tables and 4 figures 


\section{HIGHLIGHT (18 words)}

30 Increased $\mathrm{Mn}$ concentration lowers auxin concentrations in rice leaves, which suppresses

31 photosynthesis by changing stomatal function and development.

\section{ABSTRACT (176 words)}

Despite the essentiality of $\mathrm{Mn}$ in terrestrial plants, its excessive accumulation in plant tissues causes growth defects, known as Mn toxicity. Mn toxicity can be divided into apoplastic and symplastic types depending on its onset. For growth defects, symplastic rather than apoplastic Mn toxicity is hypothesised to be more critical. However, details of the relationship between growth defects and symplastic Mn toxicity remains elusive. In this study, we aimed to elucidate the molecular mechanisms of symplastic Mn toxicity in rice plants. We found that under excess $\mathrm{Mn}$ conditions, $\mathrm{CO}_{2}$ assimilation was inhibited by stomatal closure, and both carbon anabolic and catabolic activities were decreased. In addition to stomatal dysfunction, stomatal and leaf anatomical development were also altered by excess $\mathrm{Mn}$ accumulation. Furthermore, the indole acetic acid (IAA) concentration was decreased, and auxin-responsive gene expression analyses showed IAA-deficient symptoms in leaves due to excess $\mathrm{Mn}$ accumulation. These results suggest that excessive Mn accumulation causes IAA deficiency, and low IAA concentrations suppress plant growth assimilation in leaves.

\section{KEYWORDS}

53 amino acid metabolism, auxin, bundle-sheath cell, leaf anatomy, manganese, 54 photorespiration, photosynthesis, rice, respiration, stomata, 


\section{ABBREVIATIONS}

58 AOX, alternative oxidase; ARF, auxin response factor; AUX/IAA, auxin/indoleacetic acid; Cc, 59 chloroplastic $\mathrm{CO}_{2}$ partial pressure; $\mathrm{COX}$, cytochrome $c$ oxidase; $\mathrm{Ci}$, internal $\mathrm{CO}_{2}$

60 concentration in leaves; DAO, dioxygenase for auxin oxidation; D.W., dry weight; F.W., fresh

61 weight; Fv/Fm, maximum quantum yield of photosystem II; GC-MS, gas

62 chromatography-mass spectrometry; $g_{s}$, stomatal conductance; IAA, indole acetic acid;

63 ICP-OES, inductively coupled plasma optical emission spectroscopy; HPLC,

64 high-performance liquid chromatography; PODs, class III peroxidases; PS, photosystem;

65 ROS, reactive oxygen species; SEM, scanning electron microscope; SOD, superoxide

66 dismutase; TCA, tricarboxylic acid; $\mathrm{Y}(\mathrm{II})$, quantum yield of photosystem II; $\mathrm{Y}(\mathrm{I})$, quantum

67 yield of photosystem I; $\mathrm{Y}(\mathrm{NPQ})$, quantum yield of non-photochemical quenching; $\mathrm{Y}(\mathrm{NO})$,

68 quantum yield of non-radiative decay; $\mathrm{Y}(\mathrm{ND})$, quantum yield of non-photochemical

69 quenching at the donor-side of photosystem I; Y(NA), quantum yield of non-photochemical

70 quenching at the acceptor-side of photosystem I 


\section{INTRODUCTION}

$\mathrm{Mn}$ is an essential nutrient for both terrestrial plants and animals (Shao et al., 2017). With regard to terrestrial plants, Mn was first discovered in their ash, and McHargue (1922) proved that $\mathrm{Mn}$ is an essential nutrient. Manganese possesses a wide variety of physiological functions in plant cells. For example, Mn activates more than 35 different enzymes such as chloroplast RNA-polymerase, and several enzymes involved in the tricarboxylic acid (TCA) cycle and shikimic acid pathway (Broadley et al., 2012). Mn is also directly involved in the physiological function of Mn-superoxide dismutase (SOD) as a cofactor to detoxify reactive oxygen species (ROS) and oxalate oxidase (Broadley et al., 2012). Among these physiological functions, the Mn cluster within the oxygen-evolving complex of photosystem II (PSII) is crucial for driving photosynthesis in terrestrial plants (Suga et al., 2015).

Although $\mathrm{Mn}$ is indispensable for terrestrial plants, excess $\mathrm{Mn}$ accumulation in leaves reduces their growth and crop yield, through what is known as Mn toxicity (Foy et al., 1978; Li et al., 2019). The toxic effects of Mn are observed in various terrestrial plants, but the critical concentration for expressing toxicity varies depending on plant species and genotype (Foy et al., 1978; Horst et al., 1999; Horiguchi, 1987; Millaleo et al., 2010). For example, Zea mays L. shows signs of Mn toxicity at an accumulation of $200 \mu \mathrm{g} \mathrm{Mn} \mathrm{g}^{-1}$ (dry weight; D.W.) in the leaves; in contrast, Lupinus albus L. or woody Mn hyperaccumulator species, such as Gossia bidwillii, can accumulate more than 10,000 $\mu \mathrm{g} \mathrm{Mn} \mathrm{g}^{-1}$ (D.W.) without Mn toxicity symptoms (Blamey et al., 1986, 2015; Fernando et al., 2006). These differences in the critical concentration for $\mathrm{Mn}$ toxicity are derived from the different capacities of $\mathrm{Mn}$ compartments within cells (Blamey et al., 2015). Excessive $\mathrm{Mn}$ is sequestrated to vacuoles in a chelated form with organic acids (malate/citrate) to maintain the Mn concentration within cells (Blamey et al., 2015). However, when the vacuole capacity for storing Mn reaches the upper limit, the Mn concentration increases in the symplastic and 111 apoplastic regions, where Mn toxicity occurs (Horiguchi, 1987; Führs et al., 2009). In fact, 112 Mn-sensitive plants show a smaller vacuole capacity for retaining Mn than do Mn-tolerant 
113 plants (Horst et al., 1999; Blamey et al., 2015). This interpretation has been validated by

114 loss-of-function and overexpression mutants of tonoplast-localised Mn transporter proteins

115 such as metal tolerant protein (MTP) 8 and calcium exchanger (CAX) 2, which show a

116 susceptible and tolerant phenotype to Mn toxicity, respectively (Hirschi et al., 2000; Delhaize

117 et al., 2003; Chen et al., 2013; Eroglu et al., 2016). In addition to these mechanisms,

118 Mn-tolerant plants, such as Helianthus annuus L., use trichomes as Mn storage tissue to

119 avoid an excessive increase in Mn concentration within cells (Blamey et al., 1986, 2015).

120 However, this mechanism depends on the plant species and is not a general strategy to

121 prevent Mn toxicity (Blamey et al., 2015).

122 Mn toxicity can be divided into two categories depending on the cell part of its

123 onset: apoplastic and symplastic (Fernando et al., 2016). The primary symptoms of

124 apoplastic Mn toxicity in terrestrial plants are brown spots containing oxidised phenolics,

125 oxidised $\mathrm{Mn}\left[\mathrm{Mn}^{3+}\right.$ and $\left.\mathrm{Mn}^{4+}\right]$, and callose in the leaves (Kenten and Mann, 1957; Horiguchi,

126 1987; Wissemeir and Horst, 1987, 1992; Horst et al., 1999; Fecht-Christoffers et al., 2003a,

$127 b$; Blamey et al., 2015). Mn accumulation in the apoplast stimulates the expression of class

128 III peroxidases (PODs), which undertake both $\mathrm{H}_{2} \mathrm{O}_{2}$ production through NADH-peroxidase

129 activity and $\mathrm{H}_{2} \mathrm{O}_{2}$ consumption through guaiacol-peroxidase activity (Fecht-Christoffers et al.,

130 2003a, b; Führs et al., 2009). Furthermore, the concentrations of phenolics, which suppress

131 the $\mathrm{NADH}$-peroxidase activity, are lowered in the apoplast and, as a consequence, $\mathrm{H}_{2} \mathrm{O}_{2}$

132 production is accelerated in the apoplast (Fecht-Christoffers et al., 2006; Führs et al., 2009).

133 The $\mathrm{H}_{2} \mathrm{O}_{2}$ consumption reaction by the guaiacol activity of PODs also proceeds by utilising

134 phenolics in the apoplast; subsequently, the intermediate phenolic oxidation product,

135 phenoxyl radicals $\left(\mathrm{PhO}^{-}\right)$, oxidises $\mathrm{Mn}^{2+}$ to $\mathrm{Mn}^{3+}$ (Takahama, 2004). Because $\mathrm{PhO} \cdot$ is

136 regenerated to phenolics after the reaction with $\mathrm{Mn}^{2+}$, the continuous reactions of

$137 \quad \mathrm{H}_{2} \mathrm{O}_{2}$-production/consumption by the class III PODs accumulate the oxidised phenolics and

138 oxidised Mn in the apoplast (Kenten and Mann, 1957).

139 Although brownish spots are an indicator of $\mathrm{Mn}$ toxicity in terrestrial plants,

140 attenuation of plant growth by Mn toxicity is not always accompanied by the expression of 
141 brown spots in leaves (Blamey et al.,1986, 2015; Horiguchi, 1987; Wissemeier and Horst, 142 1992; González et al., 1998; Chen et al., 2013; Tsunemitsu et al., 2018). Under excess Mn 143 accumulation in the symplast, leaves show lower photosynthetic activity and lower Chl content (Nable et al., 1988; Macfie and Taylor, 1992; González and Lynch, 1997; Kitao et al.,

145 1997; Fernando and Lynch, 2015). Houtz et al. (1988) demonstrated a decrease in 146 photosynthetic activity despite the absence of brown necrotic spots on leaves grown under high $\mathrm{Mn}$ concentrations, implying that a decrease in photosynthetic activity occurred independently of apoplastic $\mathrm{Mn}$ toxicity. These characteristics are termed symplastic $\mathrm{Mn}$ toxicity (Fernando et al., 2016). The decreases in Chl concentration and photosynthetic activities have been hypothesised to be caused by photoinhibition by ROS; the decrease in photosystem I (PSI) content or the disturbance of Chl synthesis due to the inhibition of Fe absorption; Mn binding to Rubisco instead of Mg; or stomatal dysfunction (Clairmont et al., 1986; Suresh et al., 1987; Houtz et al., 1988; McDaniel and Toman, 1994; Millaleo et al., 2013). However, these hypotheses are often independently discussed at both in vivo and in vitro levels; therefore, the mechanisms by which symplastic $\mathrm{Mn}$ toxicity suppresses photosynthesis are less evident. Elucidating Mn toxicity including both its apoplastic and symplastic mechanisms would contribute to establishing a strategy for protecting terrestrial plants against Mn toxicity in agricultural land (Fernando and Lynch, 2015). Currently, the strategy for preventing $\mathrm{Mn}$ toxicity depends on two mechanisms. One is limiting $\mathrm{Mn}$ absorption and transport, and the other is Mn sequestration from the cytosol to the vacuole (Li et al., 2019). These strategies are important in preventing $\mathrm{Mn}$ toxicity. However, identifying the expression mechanisms of symplastic Mn toxicity would be informative for manipulating $\mathrm{Mn}$ toxicity in terrestrial plants without limiting the Mn transportation system.

164 This knowledge would be applicable to plant engineering processes such as $\mathrm{Mn}$ phytoremediation (Lei et al., 2007).

In this study, we investigated the mechanisms of symplastic Mn toxicity to suppress photosynthetic activity in rice leaves. Rice shows high tolerance toward Mn toxicity, which make it easy to investigate the effect of excess Mn concentrations without severe necrosis 
169 and chlorosis (Führs et al., 2010). Additionally, complete genetic information is available for

170 investigating gene expression. Previous studies have indicated that photosynthetic electron

171 transport activities on the thylakoid membrane and Rubisco isolated from leaves grown

172 under high $\mathrm{Mn}$ concentrations were robust, although $\mathrm{CO}_{2}$ assimilation was substantially

173 suppressed in leaves (Houtz et al., 1988; Nable et al., 1988; Chatterjee et al., 1994). Based

174 on these observations, we hypothesised that chloroplast proteins are not the primary targets

175 of $\mathrm{Mn}$ toxicity, but factors that modulate $\mathrm{CO}_{2}$ assimilation are targeted under $\mathrm{Mn}$ toxicity.

176 Here, we discuss how photosynthetic activity is limited under Mn toxicity conditions from a

177 wide range of physiological responses in plant cells.

178

179

180

181

182

183

184

185

186

187

188

189

190

191

192 


\section{MATERIALS AND METHODS}

\section{Plant materials and plant growth conditions}

199 Oryza sativa L. 'Nipponbare' wild-type (WT) plants were grown in hydroponic culture, as 200 reported in a previous study (Makino et al., 1994). We employed two Mn concentration 201 conditions by changing the $\mathrm{MnSO}_{4}$ application to $0.5 \mu \mathrm{M}$ (control conditions) and $200 \mu \mathrm{M}$ 202 (Mn-toxic conditions) (Tsunemitsu et al., 2018). The $\mathrm{pH}$ of the hydroponic culture was 203 adjusted to 5.2 using $\mathrm{HCl}$, and the solution was replenished twice a week. The chamber was maintained at $60 \%$ relative humidity with a $14 \mathrm{~h}$ light $\left(28{ }^{\circ} \mathrm{C}\right)$ and $10 \mathrm{~h}$ dark $\left(25^{\circ} \mathrm{C}\right)$ photoperiod. The light intensity was $500-600 \mu \mathrm{mol}$ photons $\mathrm{m}^{-2} \mathrm{~s}^{-1}$. All physiological, structural, and genetic analyses were performed for fully and newly expanded leaves after $70 \mathrm{~d}$ of germination, and the analyses were completed before heading.

\section{Leaf photosynthesis and respiration measurements in rice plants}

210 The gas exchange analysis, Chl fluorescence, and oxidised reaction centre Chl in PSI $211\left(\mathrm{P} 700^{+}\right)$were simultaneously measured using a combined system of Li-6400 (Li-COR Inc., 212 Lincoln, USA), Mini-PAM, and PAM-101 equipped with a dual-wavelength emitter-detector 213 unit (ED-P700DW) (Heinz Walz GmbH, Effeltrich, Germany) with a cold halogen lamp. 214 Ambient air $\left(40 \mathrm{~Pa} \mathrm{CO}\right.$ and $\left.21 \mathrm{kPaO}_{2}\right)$ and pure $\mathrm{CO}_{2}$ gas were mixed to maintain the $\mathrm{CO}_{2}$ concentration during measurements. The gases were saturated with water vapour at $18.0 \pm$

$2160.1{ }^{\circ} \mathrm{C}$, and the leaf temperature was maintained at $28^{\circ} \mathrm{C}$. The $\mathrm{Chl}$ fluorescence parameters $217 \mathrm{Y}(\mathrm{II}), \mathrm{Y}(\mathrm{NPQ})$, and $\mathrm{Y}(\mathrm{NO})$ were calculated as described by Baker (2008), and a measuring 218 light $\left(0.1 \mu \mathrm{mol}\right.$ photons $\left.\mathrm{m}^{-2} \mathrm{~s}^{-1}\right)$ and a saturated pulse $\left(10,000 \mu \mathrm{mol}\right.$ photons $\mathrm{m}^{-2} \mathrm{~s}^{-1}, 600$ $219 \mathrm{~ms}$ ) were employed to calculate the photosynthetic parameters of PSII. The oxidation-reduction state of P700 in PSI was determined according to the method described by Klughammer and Schreiber (1994). The maximum oxidation level of P700 (Pm) was obtained using a saturated pulse under far-red light illumination, and PSI photosynthetic parameters $[Y(I), Y(N D)$, and $Y(N A)]$ were calculated using the oxidation-reduction state of 

Ltd., King's Lynn, UK) in the aqueous phase at $25^{\circ} \mathrm{C}$ (Hachiya et al., 2010). For efficient absorption of the chemical reagent into leaves in the aqueous phase, the leaf surface was washed with $10 \%(\mathrm{v} / \mathrm{v})$ dimethyl sulfoxide, and the leaves were finely cut up. The $\mathrm{O}_{2}$ absorption rate was measured in the reaction buffer $[50 \mathrm{mM}$ $N$-(2-hydroxyethyl)piperazine- $N$-2-ethanesulfonic acid (HEPES)-KOH (pH 6.6), $10 \mathrm{mM}$ 2-( $N$-morpholino)ethanesulfonic acid, $0.2 \mathrm{mM} \mathrm{CaCl}_{2}, 50 \mathrm{mM}$ sucrose]. To evaluate the uncoupled respiration rate and alternative oxidase (AOX) and cytochrome $c$ oxidase (COX) activities in the mitochondria, $10 \mu \mathrm{M}$ carbonyl cyanide m-chlorophenyl hydrazine, $2 \mathrm{mM}$ n-propyl gallate, and $2 \mathrm{mM} \mathrm{KCN}$ were added sequentially.

\section{Quantification of leaf mineral elements and chlorophyll content}

Leaf mineral elements were analysed according to Takagi et al. (2020). Briefly, the leaf blades were dried at $70{ }^{\circ} \mathrm{C}$ and ground using a homogeniser. To determine the mineral content, except for that of $\mathrm{N}$, the dry matter was digested overnight in an acid mixture $\left(\mathrm{HNO}_{3}: \mathrm{H}_{2} \mathrm{SO}_{4}: \mathrm{HClO}_{4}=5: 1: 2\right)$. Subsequently, the solution was heated at $150{ }^{\circ} \mathrm{C}$ for $30 \mathrm{~min}$ in a heat block. After cooling, the solutions were heated again at $200{ }^{\circ} \mathrm{C}$ for $1 \mathrm{~h}$. After decomposition, the mineral contents were quantified by inductively coupled plasma optical emission spectroscopy (ICP-OES) (iCAPTM 7200; Thermo Fisher Scientific Inc., Waltham, USA). To measure the total $\mathrm{N}$ concentration in the leaves, dried leaves were decomposed using $60 \%(\mathrm{v} / \mathrm{v}) \mathrm{H}_{2} \mathrm{SO}_{4}$ with $30 \%(\mathrm{v} / \mathrm{v}) \mathrm{H}_{2} \mathrm{O}_{2}$. The $\mathrm{N}$ concentration was determined using Nessler's reagent in a decomposed solution after the addition of $10 \%(\mathrm{w} / \mathrm{v})$ potassium sodium tartrate and $2.5 \mathrm{M} \mathrm{NaOH}$, and the absorbance was measured at $420 \mathrm{~nm}$ (Takagi et al., 2017). The leaf Chl content was quantified using fresh samples with $N$, $\mathrm{N}$-dimethylformamide, as described previously (Porra et al., 1989). 
253 Leaves were sampled at the end of the day ( $1 \mathrm{~h}$ before the start of the dark period) and at

254 the end of the night ( $1 \mathrm{~h}$ before the start of the light period); subsequently, leaves were 255 frozen using liquid nitrogen. Glucose, sucrose, and starch were extracted from leaves 256 according to Morita et al. (2015) and quantified using the Enzytech ${ }^{\mathrm{TM}}$ D-Glucose/Sucrose kit 257 (R-Biopharm AG, Darmstadt, Germany).

\section{Quantification of leaf amino acid contents}

260 The leaves were homogenised using $10 \mathrm{mM} \mathrm{HCl}$ with liquid nitrogen. After centrifugation

$261\left(15,000 \times g, 4{ }^{\circ} \mathrm{C}, 5 \mathrm{~min}\right)$, the supernatant was applied to a centrifugation filter (Amicon Ultra $2620.5 \mathrm{~mL} 3 \mathrm{~K}$ device; Merck KGaA, Darmstadt, Germany), and the fraction containing free amino acids was obtained by centrifugation $\left(15,000 \times g, 4{ }^{\circ} \mathrm{C}, 10 \mathrm{~min}\right)$. The amino acid was labelled using AccQ-Tag Ultra Derivatization Kit (Waters Co., Milford, USA) according to the manufacture's instructions, and the free amino acids were separated using an HPLC system. The HPLC system consisted of a 305 Piston Pump as the system controller and a 306 Pump as a multi-pump application equipped with an 811D Dynamic Mixer and 805 Manometric Module, using the Trilution LC software (Gilson, Villiers le Bel, France). The sample solution was manually injected into the HPLC system. The derivative amino acids were separated on a Sepax Bio-C18 ( $44.6 \times 250$ mm) (Sepax Technologies, Inc., Newark, USA) and eluted by $100 \%$ solvent $\mathrm{A}\left[5 \%(\mathrm{v} / \mathrm{v})\right.$ methanol in $\left.20 \mathrm{mM} \mathrm{CH}_{3} \mathrm{COONa}(\mathrm{pH} 6.5)\right]$ for 4 min after injection and by a linear gradient of $94 \%$ solvent $A$ to $30 \%$ solvent B (100\% acetonitrile) for another 65 min. The column was washed with $100 \%$ solvent B for 20 min and equilibrated with $100 \%$ solvent $A$ for $16 \mathrm{~min}$. The flow rate was $0.6 \mathrm{~mL} \mathrm{~min}^{-1}$, and the column temperature was maintained at $25^{\circ} \mathrm{C}$ by incubation in a hot pocket (Thermo Fisher Scientific Inc., Waltham, USA). The peaks derived from derivatised amino acids were detected using UV/VIS-155 (Gilson, Villiers le Bel, France).

280 The TCA cycle enzyme activities in the leaf blades were determined according to Noguchi 
281 and Terashima (2006). Briefly, the leaves were homogenised with the extraction buffer [100 282 mM HEPES-KOH (pH 7.5), $10 \mathrm{mM} \mathrm{KH}_{2} \mathrm{PO}_{4}, 0.5 \mathrm{mM}$ EDTA-Na, $10 \mathrm{mM}$ dithiothreitol, $0.05 \%$ 283 (v/v) TritonX-100, and 20\% (v/v) glycerol] with polyvinylpyrrolidone. The reaction medium was prepared for each enzyme according to the previous study, and the enzyme activity was determined at $30^{\circ} \mathrm{C}$ using UV-160A equipped with a temperature control system (Shimadzu, Kyoto, Japan).

\section{Structural analysis of stomata complex and leaf cross-section}

For scanning electron microscopic analysis, the leaves were fixed with half-strength Karnovsky's solution [50 mM phosphate buffer ( $\mathrm{pH} 7.2), 2.5 \%(\mathrm{v} / \mathrm{v})$ glutaraldehyde, $2 \%(\mathrm{v} / \mathrm{v})$ paraformaldehyde] with vacuum infiltration for $3 \mathrm{~h}$. After fixation, the leaves were washed with the phosphate buffer and dehydrated using a dilution series of ethanol, followed by t-butanol. Leaves were dried using a t-butanol freeze drier (Vacuum Device Inc., Ibaraki, Japan) and coated with Pt (JEC-300FC; JEOL Ltd., Tokyo, Japan). The stomatal complex structure was monitored using a JSM-IT200 scanning electron microscope (JEOL Ltd., Tokyo, Japan). The size of the stomatal complex, comprising the paired guard cells, the paired subsidiary cells, and the pore itself, and the stomatal density were analysed using SEM Operation software (JEOL Ltd., Tokyo, Japan). Under each growth condition, the size of the stomata complex and the stomatal density were analysed on an independent section of the leaves as indicated in figure legends of six biologically independent plants. To analyse the vertical and horizontal leaf sections, leaves were sectioned and fixed with formalin-acetate-alcohol (FAA) [63\% (v/v) ethanol, 5\% (v/v) acetic acid, 5\% (v/v) formalin] with vacuum infiltration for $1 \mathrm{~h}$, followed by incubation at $4{ }^{\circ} \mathrm{C}$ for $2 \mathrm{~d}$. The leaves were dehydrated using a dilution series of ethanol, followed by n-butanol. The dehydrated leaves were embedded in paraffin and were sectioned at $10 \mu \mathrm{m}$ thickness using an RX-860 microtome (Yamato Kohki Industrial Co., Ltd., Saitama. Japan). The FAA-fixed leaf sections were stained with $0.05 \%(\mathrm{w} / \mathrm{v})$ toluidine blue $\mathrm{O}$. To investigate the intact leaf sections, leaves were embedded in $50 \mathrm{mM}$ phosphate buffer $(\mathrm{pH} 7.2)$ containing $5 \%(\mathrm{w} / \mathrm{v})$ agar. The 
309 agar-embedded leaves were sectioned at a thickness of $30 \mu \mathrm{m}$ using DTL-1000 vibratome

310 (Dosaka EM Co., Ltd., Kyoto, Japan). Intact leaf sections and FAA-fixed leaf sections were

311 analysed using an optical microscope (BX53; Olympus Co., Japan).

\section{Indole acetic acid quantification}

314 The IAA content in leaves was quantified using a GC-MS system, according to Nghi et al.

315 (2021). Briefly, the leaves were homogenised in $70 \%(\mathrm{v} / \mathrm{v})$ cold acetone. After centrifugation,

316 the supernatant was reduced to the aqueous phase by vacuum centrifugation equipped with

317 a cold trap. Subsequently, $\mathrm{HCl}(0.1 \mathrm{mM})$ was added to adjust the $\mathrm{pH}$ to 2.8 , and diethyl ether

318 was added to dissolve IAA into the diethyl ether fraction. The diethyl ether fraction was dried

319 under vacuum and subsequently dissolved in N,O-bis(trimethylsilyl) tri-fluoroacetamide

320 (BSFTA) containing 1\% trimethylchlorosilane. IAA was silylated at $70{ }^{\circ} \mathrm{C}$ for $1 \mathrm{~h}$. The

321 silylated IAA was identified using a GC-MS-QP2010 SE (Shimadzu, Kyoto, Japan) with a

322 DB-WAX column. The conditions for GC-MS analysis were the same as those described 323 previously (Fujii et al., 2010). The silylated IAA was identified by fragment ion $202(\mathrm{~m} / \mathrm{z}$ ) and 324 molecular ion 319 (m/z) (Ljung et al., 2005; Gutierrez et al., 2009; Nghi et al., 2021).

\section{Gene expression analysis}

327 To investigate gene expression in rice leaves, mRNA was isolated from the leaf blades 328 according to Suzuki et al. (2004). After mRNA isolation, cDNA was synthesised using 329 PrimeScript ${ }^{\text {TM }}$ RT Reagent Kit (Takara Bio Inc., Shiga, Japan), and the mRNA content was 330 quantified by real-time PCR using the LightCycler® 96 System (Roche Diagnostics K.K., 331 Tokyo, Japan) with a KAPA SYBR FAST One-Step qRT-PCR Kit (Nippon Genetics Co., Ltd,

332 Tokyo, Japan). The primer sequences used for real-time PCR analyses are listed in 333 Supplementary Table S1.

\section{Simulation of $\mathrm{CO}_{2}$ fixation rate according to biochemical photosynthetic model}

336 Rubisco limited $\mathrm{CO}_{2}$ fixation rate was calculated from the equation of von Caemmerer and 
337 Farquhar (1981):

$338 \quad \mathrm{~A}=\mathrm{EV}_{\mathrm{c}}\left(\mathrm{Cc}-\Gamma^{\star}\right) /\left[\mathrm{Cc}+\mathrm{K}_{\mathrm{c}}\left(1+\mathrm{O} / \mathrm{K}_{\mathrm{o}}\right)\right]-\mathrm{Rd},(1)$

339 Where $E$ is the amount of Rubisco protein (assumed to be $5.3 \mu \mathrm{mol} \mathrm{m}{ }^{-2}$, from rice grown

340 with hydroponic solution same as in the present study described by Suganami et al. 2021),

$341 \quad V_{c}$ is the Rubisco activity of carboxylation, $\mathrm{Cc}$ is the chloroplastic $\mathrm{CO}_{2}$ partial pressure, $\mathrm{O}$ is

342 the partial pressure of $\mathrm{O}_{2}$ in the chloroplast (assumed to be the same as in the atmosphere,

$34321 \mathrm{kPa}$ ), $\mathrm{K}_{\mathrm{c}}$ and $\mathrm{K}_{\mathrm{o}}$ are the Michaelis-Menten constants for $\mathrm{CO}_{2}$ and $\mathrm{O}_{2}$, and $\mathrm{Rd}$ is the day

344 respiration (assumed to be $1.0 \mu \mathrm{mol} \mathrm{m} \mathrm{m}^{-2} \mathrm{~s}^{-1}$. $\Gamma^{*}$ is the $\mathrm{CO}_{2}$ compensation point of

345 photosynthesis in the absence of Rd as defined as follows:

$346 \quad \Gamma^{*}=0.5 \mathrm{~V}_{\mathrm{o}} \mathrm{K}_{\mathrm{c}} \mathrm{O} / \mathrm{V}_{\mathrm{c}} \mathrm{K}_{\mathrm{o}},(2)$

347 where $\mathrm{V}_{\mathrm{o}}$ is the Rubisco activity of oxygenation. $\mathrm{Mg}^{2+}$-binding Rubisco kinetics were taken

348 from Makino et al., (1988). $\mathrm{Mn}^{2+}$-binding Rubisco kinetics were calculated by multiplying the

349 average ratio of $\mathrm{Mn}^{2+} / \mathrm{Mg}^{2+}$-binding Rubisco kinetics and $\mathrm{Mg}^{2+}$-binding Rubisco kinetics. The

350 average ratio of $\mathrm{Mg}^{2+} / \mathrm{Mn}^{2+}$-binding Rubisco kinetics were calculated by the data from Bloom

351 and Kameritsch (2017). Rubisco kinetics were summarized in Supplementary Table S2.

352 Photorespiration rate were was calculated from the equation of von Caemmerer and

353 Farquhar (1981):

$354 \quad \mathrm{~F}=0.5 \mathrm{EV}_{\mathrm{o}} \mathrm{O} /\left(\mathrm{O}+\mathrm{K}_{\mathrm{o}}\left(1+\mathrm{Cc} / \mathrm{K}_{\mathrm{c}}\right),(3)\right.$

\section{Statistical analysis}

357 All measurement data are expressed as means \pm standard deviation (SD), or box plots with 358 bars indicating the $1.5 \times$ interquartile range $(\mathrm{IQR})$ and with squares indicating the mean 359 value of at least three independent biological analyses. Significant differences in 360 physiological and biological parameters between the control- and Mn-toxic conditions were 361 detected by the non-parametric Kruskal-Wallis test. All statistical analyses were performed using Origin Pro 2020 (LightStone Corp., Tokyo, Japan). 


\section{RESULTS}

\section{Phenotypes of rice grown under Mn-toxic conditions}

367 To study the effects of Mn toxicity, Oryza sativa L. 'Nipponbare' was grown under high Mn 368 concentrations (200 $\mu \mathrm{M}$; Mn-toxic conditions) in hydroponic culture for $70 \mathrm{~d}$ after 369 germination. Under Mn-toxic conditions, the leaves showed pale green and brown-coloured sections, especially at the tips (Fig. 1A, B). These observations correspond with typical Mn toxicity symptoms in rice leaves (Vlamis and Williams, 1964; Chen et al., 2013). Compared with the control conditions, Mn-toxic conditions decreased the total dry weight of rice, especially the dry matter of the leaf sheath and root (Fig. 1C, D).

To study the effects of high Mn application on leaf mineral composition, the leaf mineral concentrations were quantified. The leaf $\mathrm{Mn}$ concentration was significantly increased under Mn-toxic conditions (Fig. 2). This concentration was comparable to that of WT rice, which showed growth inhibition when grown at a concentration of 1,000 $\mu \mathrm{M} M n$ for 3 weeks (Sasaki et al., 2011). The K, Ca, and Fe concentrations were similar under the control and Mn-toxic conditions (Fig. 2). In contrast, the $\mathrm{Mg}, \mathrm{Zn}$, and $\mathrm{Cu}$ concentrations increased under Mn-toxic conditions (Fig. 2). These results demonstrated decreased growth and the Mn toxicity symptoms accompanied by Mn accumulation in leaves grown under Mn-toxic conditions.

Mn-toxic conditions suppressed $\mathrm{CO}_{2}$ assimilation by limiting stomatal conductance in leaves

Next, the steady-state photosynthetic activities were measured under ambient air conditions (40 $\mathrm{Pa} \mathrm{CO}$ and $21 \mathrm{kPaO}_{2}$ ). The $\mathrm{CO}_{2}$ assimilation rate was significantly decreased under the high light irradiance by the Mn-toxic treatments (Fig. 3A). The Mn-toxic treatments showed lower stomatal conductance $\left(g_{s}\right)$ than did the control plants, and the change in $g_{\mathrm{s}}$

390 with increasing light intensity was also suppressed (Fig. 3B). These stomatal responses to

391 the increase in Mn concentration were consistent with previous studies (Suresh et al., 1987;

392 Nable et al., 1988; González and Lynch, 1997; Lidon et al., 2004; Santos et al., 2017). The 
393 internal $\mathrm{CO}_{2}$ concentration in leaves (Ci) was lower under the Mn-toxic conditions than 394 under control conditions (Fig. 3C). These results indicated that, under Mn-toxic conditions, 395 the stomata limit $\mathrm{CO}_{2}$ diffusion into leaves and $\mathrm{CO}_{2}$ assimilation is suppressed, particularly 396 under high light conditions.

397 In addition to the $\mathrm{CO}_{2}$ assimilation rate, the photosynthetic electron transport 398 activities in both PSII and PSI were analysed by chlorophyll fluorescence and $399 \mathrm{P} 700^{+}$-dependent absorbance changes in the leaves. The quantum yield of PSII [Y(II)] was 400 lower under Mn-toxic conditions than under control conditions at the high light irradiance 401 (Fig. 3D). This result indicated that the electron transport activity in PSII was suppressed at 402 the high light irradiance, but compared with the $\mathrm{CO}_{2}$ assimilation rate, the change in $\mathrm{Y}$ (II) 403 was marginal. The quantum yield of non-photochemical quenching [Y(NPQ)] increased 404 similarly with the increase in light intensity under both control and Mn-toxic conditions (Fig. $4053 \mathrm{E})$. The quantum yield of non-radiative energy loss [Y(NO)] was different between the 406 control and Mn-toxic conditions under low light irradiance; however, this difference was 407 masked under high light irradiance (Fig. 3F). These results showed that the photoprotective 408 mechanisms in PSII are robust, but the redox state in PSII can be perturbed under Mn 409 toxicity. The quantum yield of $\mathrm{PSI}[\mathrm{Y}(\mathrm{I})]$ showed similar kinetics to that of $\mathrm{Y}(\mathrm{II})$, and no 410 significant differences were observed between the control and Mn toxic condition (Fig. 3G).

411 The quantum yield of non-photochemical quenching at the donor side of PSI [Y(ND)] was 412 higher under Mn-toxic conditions than under the control conditions at high light irradiance 413 (Fig. 3H). In contrast, the quantum yield of non-photochemical quenching at the acceptor 414 side of PSI [Y(NA)] was lower under Mn-toxic conditions than under the control conditions at 415 high light irradiance (Fig. 3I). These results indicated that the whole-chain photosynthetic 416 electron transport rate was less affected under Mn-toxic conditions than under the control 417 conditions; however, the photosynthetic electron transport reaction was limited to the donor 418 side of PSI, and PSI was more oxidised under Mn-toxic conditions than under the control 419 conditions.

420 The maximum quantum yield of PSII (Fv/Fm) was significantly, but marginally 
421 decreased under Mn-toxic conditions (Fig. 2J). The total Chl content in leaves was also

422 decreased under Mn-toxic conditions (Fig. 2K). These results indicated that Mn toxicity

423 stimulates PSIl photoinhibition. In contrast, the total $\mathrm{N}$ concentration was not significantly

424 different between the control and Mn-toxic conditions (Fig. 2L). Based on the linear function

425 between the $\mathrm{N}$ and Rubisco concentrations in the leaves (Nakano et al., 1997), this result

426 indicated that the quantity of Rubisco was less affected by Mn toxicity.

427

428 Carbohydrate metabolism in leaves grown under Mn-toxic conditions

429 To examine whether the suppression of photosynthesis by excessive $\mathrm{Mn}$ accumulation 430 affects carbon acquisition during growth, the major carbohydrate concentrations were 431 quantified in the leaves. Leaves were sampled at both the end of the day and the end of the 432 night to visualise the $\mathrm{CO}_{2}$ assimilation activity during the day (Takagi et al., 2016a). At the 433 end of the day, Mn-toxicity treatments showed lower sucrose concentrations in the leaves

434 than did the control plants (Fig. 4). In contrast, at the end of the night, the sucrose 435 concentration was similar under both control and Mn-toxic conditions (Fig. 4). The glucose 436 and starch concentrations were lower than the sucrose concentration under both control and 437 Mn-toxic conditions, and significant differences were not detected between the growth 438 conditions at the end of the day and the end of the night (Fig. 4). The sum of the sucrose, 439 glucose, and starch concentrations was lower in leaves grown under Mn-toxic conditions at 440 the end of the day, but the sum of these carbohydrate concentrations was similar between 441 the growth conditions at the end of the night (Fig. 4). These results indicated that carbon 442 acquisition is suppressed, corresponding to lower $\mathrm{CO}_{2}$ assimilation activities, in leaves 443 grown under Mn-toxic conditions.

\section{Effects of Mn toxicity on mitochondrial respiration in the leaves}

446 The carbohydrates fixed during the day are metabolised at night and consumed at a 447 constant rate from the beginning of the night to the dawn (Moraes et al., 2019). Therefore, 448 the difference in carbohydrate concentrations between the end of the day and end of the 
449 night indicates the carbon catabolic activity during the night (Takagi et al., 2016a). To

450 confirm whether carbon catabolism is suppressed under Mn-toxic conditions (Fig. 4), leaf

451 respiration was examined under control and Mn-toxic conditions. The respiratory $\mathrm{CO}_{2}$

452 emission rate was decreased under Mn-toxic conditions (Fig. 5A). To examine the effect of

453 the change in respiration activities on carbon catabolism, the leaf amino acid content was

454 quantified during the night (Sulpice et al., 2014). Subsequently, the Asp, Glu, and Gly contents were significantly decreased, and the Ser content was increased under Mn-toxic conditions (Fig. 5B). These results indicated that carbon catabolism is affected by Mn-toxic conditions during the night.

Next, we investigated the effects of $\mathrm{Mn}$ toxicity on the mitochondrial enzymes involved in respiration. First, the respiratory electron transport activities were measured in the presence of sucrose and mitochondrial electron transport inhibitors in vivo using an aqueous phase $\mathrm{O}_{2}$-electrode (Hachiya et al., 2010). In the absence of inhibitors, the $\mathrm{O}_{2}$ consumption rate did not differ between the control and Mn-toxic conditions (Fig. 5C). CCCP dissipated mitochondrial membrane potential $\left(\Delta \Psi_{\mathrm{m}}\right)$ and similarly stimulated $\mathrm{O}_{2}$ consumption rate in both leaves grown under the control and Mn-toxic conditions (Fig. 5C). The COX and AOX activities in the presence of CCCP and sucrose were determined by adding n-propyl gallate and KCN. Subsequently, the control and Mn-toxic conditions showed similar $\mathrm{O}_{2}$ consumption rates depending on the COX and AOX activities (Fig. $5 \mathrm{C}$ ). The effect of $\mathrm{Mn}$ toxicity on mitochondrial respiratory electron transport activity was reproduced when these activities were determined on a leaf fresh-weight basis (Supplementary Fig. S1).

470 These results indicated that under sucrose feeding, the mitochondrial respiratory electron transport activities were similar between the control and Mn-toxic conditions.

To understand the effects of Mn toxicity on the enzyme activities of the TCA-cycle,

473 the six types of TCA cycle enzyme activities were determined on both leaf area and 474 fresh-weight basis. NADP-isocitrate dehydrogenase, NAD-isocitrate dehydrogenase,

475 NAD-malate dehydrogenase, and aconitase showed similar activities under the control and 476 Mn-toxic conditions (Fig. 5D-G, I, Supplementary Fig. S2). The NAD-malic enzyme activity 
477 decreased under Mn-toxic conditions (Fig. 5H, Supplementary Fig. S2), whereas the

478 fumarase activity increased (Fig. 5I, Supplementary Fig. S2). These results indicated that

479 Mn toxicity did not completely suppress the enzyme activities of the TCA cycle, but

480 specifically stimulated fumarase and suppressed NAD-malic enzyme activities.

481

Difference in stomatal development in the leaves between the control and Mn-toxic conditions

484 To examine whether the decrease in $g_{s}$ under Mn-toxic conditions was related to the change in stomatal structure and development, the stomatal complex on the adaxial side of a leaf was monitored. The stomatal complex, consisting of guard and subsidiary cells, was located linearly to the vein under the control conditions (Fig. 6A). However, under Mn-toxic conditions, the stomatal complex showed a more scattered distribution (Fig. 6B). The stomatal density increased under Mn-toxic conditions (Fig. 6C). In contrast, the size of the stomatal complex evaluated by the maximum major and minor axis was smaller under Mn-toxic conditions than under control conditions (Fig. 6A, B, D, E). The changes in stomatal size were consistent with a previous study evaluating rice stomata structure under excess Mn application (Lidon, 2002). These results indicated that Mn-toxic conditions change stomatal development in the leaves.

\section{Anatomical changes within a leaf blade grown under Mn-toxic conditions}

Following the change in stomatal development on the leaf epidermis, the leaf anatomy was also examined. Figure 7A shows the horizontal and vertical cross-sections of the leaves against the vein. Apparent internal air spaces were observed within leaves grown under control conditions. In contrast, cells were highly condensed in leaves grown under Mn-toxic conditions, and the internal air space was hardly observed (Fig. 7A). These results showed that in addition to stomatal complex, leaf anatomical development was also altered under Mn-toxic conditions. 
505 under Mn-toxic conditions (Fig. 7A). To investigate whether the brown spots were artifacts

506 caused by the chemical fixing treatment, intact leaf sections were also studied.

507 Subsequently, we found that the brownish spots natively existed in the bundle-sheath cells,

508 both small and large bundles gown under Mn-toxic conditions (Fig. 7B, C). These results

509 indicated that under Mn-toxic conditions, rice leaves caused apoplastic Mn toxicity-like

510 symptoms in addition to symplastic Mn toxicity, and the symptoms are more evident in the

511 bundle-sheath cells in rice leaves.

512

513 Auxin content in the leaves and mRNA expression of auxin-responsive genes

514 Our findings demonstrated that excess Mn accumulation affects the developmental process

515 of leaves. IAA is an important hormone that determines cell fate and differentiation in plants

516 (Perrot-Rechenmann, 2010). Morgan et al. (1966) reported that Mn toxicity stimulates IAA

517 oxidation activity in cotton leaves, indicating that the auxin concentration could be lowered

518 by accelerated auxin degradation in leaves under excess Mn conditions. To examine this

519 possibility, the IAA concentration in leaves was quantified by GC-MS. Figure 8A shows the

520 total ion chromatograms (TIC) with fragment ion chromatograms of the $202(\mathrm{~m} / \mathrm{z})$ and 319

$521(\mathrm{~m} / \mathrm{z})$ of the IAA standard and leaf extract from the control and Mn-toxic conditions (Fig 8A)

522 (see Materials and Methods). Subsequently, this analysis revealed that the IAA

523 concentration was significantly decreased by $76 \%$ in the leaves under Mn-toxic conditions

524 (Fig. 8B).

525 To confirm that the decrease in IAA concentration affects physiological reactions

526 within the leaves, the IAA-responsive gene expression was investigated. OsARF1,

527 OsARF15, OsARF16, OsAUX/IAA1, and OsAUX/IAA24 showed increases in their

528 expression level with an increase in IAA concentration in the leaves (Waller et al., 2002; Jain

529 et al., 2006; Wang et al., 2007). Among these genes, the expression levels of OsARF1,

530 OsARF16, and OsAUX/IAA1 were significantly decreased under Mn-toxic conditions (Fig.

531 8C). OsARF15 showed similar trends to other ARF genes, but the difference was not 532 significant between the growth conditions. In contrast, OsAUX/IAA24, and OsACT1-1 
533 showed comparable expression levels between the control and Mn-toxic conditions (Fig.

$5348 \mathrm{C}$ ). From these results, the auxin-responsive gene expression indicated a lower IAA

535 concentration in leaves under Mn-toxic conditions in concert with the results of GC-MS

536 although all genes were not responded to equally.

537 To regulate auxin concentration in plant cells, DIOXYGENASE FOR AUXIN

538 OXIDATION (DAO) undertakes IAA catabolism to maintain IAA homeostasis by oxidising

539 IAA to an inactive form, oxindole-3-acetic acid, in plant cells (Zhao et al., 2013). Because

540 Mn-toxicity stimulates oxidative IAA degradation in vitro (Morgan et al., 1966), we

541 hypothesised that OsDAO is upregulated following an increase in Mn concentration;

542 however, the transcriptional activation of OsDAO was suppressed under Mn-toxic conditions

543 (Fig. 8). The expression of OsDAO is activated under high IAA concentrations to maintain

544 IAA concentrations in plant tissues (Zhao et al., 2013). Based on this homeostatic response

545 of OsDAO, the decrease in OsDAO expression under Mn-toxic conditions would be a

546 consequence of the lower IAA concentration in leaves to avoid further inactivation of IAA. 


\section{DISCUSSION}

562 In acidic or waterlogged agricultural fields, $\mathrm{Mn}$ is easily released from the soil and causes

563 Mn toxicity in crop plants (Fernando et al., 2016). In addition to the current agricultural 564 situations, the effects of climate change, such as the rises in the atmospheric temperature 565 and the frequency of flooding or acidic rainfall, can further accelerate $\mathrm{Mn}$ dissolution in soils 566 (Fernando and Lynch, 2015). Therefore, the mechanisms of Mn toxicity should be elucidated to manipulate the future threat of increasing $\mathrm{Mn}$ availability on agricultural lands. To address the mechanisms of symplastic Mn toxicity, we investigated the physiological effects of high Mn application in rice. In this study, we propose that the disturbance of IAA homeostasis is one of the critical causes of symplastic Mn-toxicity in rice leaves.

\section{Mn toxicity disturbs IAA homeostasis and attenuates auxin signalling in the leaves}

Our results showed that the IAA concentration was decreased in the leaves under Mn-toxic conditions (Fig. 8). A previous study demonstrated that IAA oxidation activity increased in leaf extracts grown under high $\mathrm{Mn}$ concentration conditions (Morgan et al., 1966). Our observations suggest that the increase in IAA oxidation activity functions in vivo. In addition to the decrease in $A R F$ and $A U X / I A A$ gene expression levels in rice, the microRNA expression profiles revealed that miRNA160 which targets $A R F$ genes was downregulated, and miRNA164 which targets the auxin-signal related F-box protein (TRANSPORT INHIBITOR RESPONSE 1, TIR1) was upregulated in the leaves of common beans under Mn toxicity (Valdés-López et al., 2010). From these observations, we suggest that $\mathrm{Mn}$ toxicity affects the auxin signalling cascade at the transcriptional level by decreasing the IAA concentration in the leaves.

We suggest that the decrease in IAA concentration, together with the change in auxin signalling activities, causes a change in leaf anatomy and stomatal patterning/development under Mn-toxic conditions. When IAA deficiency is caused by the overexpression of GRETCHEN HAGEN3 which conjugates IAA to amino acids or the anion peroxidase which oxidatively inactivates IAA in planta, the leaf cell size becomes smaller 
589 and the leaf anatomy shows more condensed cell structures (Lagrimini et al., 1997a, b; Du et 590 al., 2012). Alternatively, the transgenic plants that inhibit auxin signalling or auxin polar 591 transport activities represent the IAA-deficient phenotype and show the abnormal leaf 592 anatomical development (Pérez-Pérez et al., 2010; Guo et al., 2013; Qi et al., 2014; 593 Muñoz-Nores et al., 2017). The aforementioned relationships among the IAA-deficient 594 phenotypes and the change in leaf structure caused by attenuating auxin signal transduction 595 are similar to those among the leaf phenotypes under Mn-toxic conditions (Figs. 3B, 6). 596 Moreover, stomatal development is regulated by auxin signalling (Balcerowicz and Hoecker, 597 2014). Exogenous IAA application decreased stomatal density in a concentration-depending 598 manner; whereas the attenuation of ARF-dependent auxin signal transduction increased it 599 (Le et al., 2014; Zhang et al., 2014). Based on these results, a decrease in IAA 600 concentrations could affect the change in leaf development and stomatal

601 patterning/development.

Generally, the terrestrial plants with smaller stomata and higher stomata density show higher transpiration ability than those with larger stomata and lower density (Franks and Beerling, 2009). This relationship does not apply to $g_{s}$ and stomatal patterning (Figs. 3B, $6 \mathrm{C})$; therefore, additional factors to suppress stomatal opening should exist under $\mathrm{Mn}$ toxicity. IAA stimulates stomatal opening by activating plasma membrane $\mathrm{H}^{+}$-ATPase (Jezek and Blatt, 2017), and the exogenous application of IAA stimulates stomatal opening in the leaves (Klein et al., 2003). Therefore, the decrease in $g_{s}$ could be caused by reducing the IAA concentration in the leaves. However, the regulation of stomatal function is quite complex, and the ROS and organic acid composition are also determinants of stomatal movement (Jezek and Blatt, 2017). Considering the stimulation of oxidative stress under Mn toxicity (see the following discussion), the decrease in IAA would not be the only cause of stomatal dysfunction. Interestingly, fumarase activity increased under Mn toxicity (Fig. 5I). Because the increase in malate/fumarate ratio is important for stomatal opening (Araújo et al., 2011), the increased fumarase activity might be a counteraction toward stomatal dysfunction under Mn toxicity. 
toxicity at the molecular level. Further research is required on a molecular genetic basis to elucidate the key factors that cause IAA deficiency. We now consider the possibility that IAA oxidation can be undertaken by unknown proteins such as class III PODs as reported previously (Ray, 1958; Lagrimini et al., 1997a, b; Tognetti et al., 2012). Because IAA is transported through the apoplast, the increase in POD activity in the apoplast might influence IAA catabolism under Mn toxicity (Robert and Friml, 2009).

\section{Suppression of photosynthesis is caused by stomatal dysfunction in rice}

We suggest that the simultaneous prolonged limitation of the $\mathrm{CO}_{2}$ assimilation reaction and stimulation of photorespiration caused oxidative stress by ROS under Mn toxicity. Under Mn toxicity, ROS-scavenging enzyme activities are upregulated in various terrestrial plants (Gonzáletz et al., 1988; Lei et al., 2007; Santos et al., 2017). This response indicates that oxidative stress is stimulated by ROS in cells under Mn toxicity. Furthermore, Houtz et al. (1988) showed an increase in the RuBP concentration in leaves under Mn toxicity. This result indicated that the turnover of photosynthates is limited by Rubisco activity (Suzuki et al., 2012). Here, $g_{s}$ was lowered and the $\mathrm{CO}_{2}$ assimilation rate was limited under Mn-toxic conditions (Fig. 2B). In contrast to the $\mathrm{CO}_{2}$ assimilation rate, which showed a $39 \%$ decrease

636 This difference would have been caused by the difference in the electron distribution between carboxylation and oxygenase reaction by Rubisco (Takagi et al., 2016b; Wada et al., 2019). Even when the $\mathrm{CO}_{2}$ availability within chloroplasts is limited by stomatal closure, $\mathrm{O}_{2}$ can diffuse within the leaves; therefore, Rubisco drives photorespiration (Zivcak et al., 2013). Under such conditions, and the proton motive force is built up to stimulate luminal acidification of the thylakoid membranes owing to the lower ATP consumption rate in the photorespiration reaction compared with that in the carboxylation reactions in the

643 Calvin-Benson cycle (Takagi et al., 2016b, 2017). Luminal acidification is represented by an increase in $Y(N D)$ (Fig. 3), which is increased by limiting the electron flow from 
645 plastoquinone to cytochrome $b_{6} f$ depending on the luminal acidification (Kramer et al., 1999),

646 under Mn-toxic conditions. These results indicated that $\mathrm{Mn}$ toxicity stimulates

647 photorespiration via stomatal closure. The increase in photorespiration activity can also be

648 supported by the change in the Gly/Ser ratio under Mn-toxic conditions (Fig. 5B). Wada et al.

649 (2019) reported that the limitation of the $\mathrm{CO}_{2}$ assimilation rate by drought stress with a

650 decrease in $g_{s}$ stimulates PSI photoinhibition rather than PSIl photoinhibition by ROS. A

651 similar situation would occur under Mn toxicity, which is why the decrease in PSIl activity is

652 modest, although PSI inhibition is accentuated under Mn-toxic conditions (Kitao et al., 1997;

653 Lidon et al., 2004; Millaleo et al., 2013). Previous studies have shown that Mn toxicity

654 targets PSI by attenuating Fe absorption (Andressen et al., 2018). However, the 655 concentration was maintained within a sufficient range for Fe nutrition in rice [from 70 to 300

$656 \mu \mathrm{g} \mathrm{g}^{-1}$ (D.W.)] (Fageria and Stone, 2008). Furthermore, a decrease in the PSI content 657 caused an increase in $Y(N A)$, instead of $Y(N D)$ during steady-state photosynthesis (Brestic 658 et al., 2015). Hence, we suggest that the decrease in PSI content due to Mn toxicity would 659 be caused not only by the Fe status but also by PSI photoinhibition, as a consequence of 660 limited $\mathrm{CO}_{2}$ assimilation. Other nutrients such as $\mathrm{Ca}, \mathrm{Mg}$ and $\mathrm{Zn}$ were also reported to be deficient under Mn toxicity (Broadley et al., 2012). We did not observe a decrease in these minerals in the leaves, but rather increased $\mathrm{Mg}, \mathrm{Cu}$, and $\mathrm{Zn}$ concentrations under $\mathrm{Mn}$ toxicity (Fig. 2). Because Cu/Zn-type SOD activities are upregulated under Mn toxicity 664 (Gonzáletz et al., 1988; Lei et al., 2007; Santos et al., 2017) and Mg supply rescues Mn toxicity symptoms (Broadley et al., 2012), the requirement of these minerals might be upregulated.

Our results suggest that chloroplasts have homeostatic systems to evade excessive Mn accumulation. In vitro studies have shown that excess free Mn stimulates ROS production by PSII and causes severe oxidative damage to thylakoid lipids and PSII (Panda et al., 1987). Although the Mn concentration was high (Fig. 2), clear evidence of severe damage to PSII was not detected here (Fig. 3J). Furthermore, Mn is to bind Rubisco, and an in vitro study indicated that the substitution of $\mathrm{Mg}^{2+}$ with $\mathrm{Mn}^{2+}$ decreases the 
673 specificity of Rubisco for $\mathrm{CO}_{2}$ (Jordan and Ogren, 1983; Bloom and Kameritsch, 2017).

674 Previous studies have suggested that Mn binding to Rubisco causes a decrease in 675 photosynthesis under Mn toxicity (Houtz et al., 1988; Kitao et al., 1997). However, the 676 contribution of $\mathrm{Mn}$-binding Rubisco to decrease $\mathrm{CO}_{2}$ assimilation reactions remains 677 unknown under Mn-toxic conditions in vivo (Houtz et al., 1988; Chatterjee et al., 1994). To 678 address this question, we simulated the change in $\mathrm{CO}_{2}$ fixation rate between $\mathrm{Mg}^{2+}$ - and $679 \mathrm{Mn}^{2+}$-binding Rubisco using photosynthetic biochemical model (von Caemmerer and 680 Farquhar, 1981). Calculated $\mathrm{CO}_{2}$ assimilation rate using $\mathrm{Mn}^{2+}$-binding Rubisco kinetics was negative value below $\mathrm{Cc}=50 \mathrm{~Pa}$ and greatly decreased compared to calculated $\mathrm{CO}_{2}$ assimilation rate using $\mathrm{Mg}^{2+}$-binding Rubisco kinetics (Supplementary Fig. S3). However, such a drastic decrease in $\mathrm{CO}_{2}$ assimilation rate was not observed (Fig. 3). Although $\mathrm{Mn}^{2+}$-binding Rubisco showed a higher photorespiration rate than $\mathrm{Mg}^{2+}$-binding Rubisco, this difference cannot compensate the difference in $\mathrm{CO}_{2}$ assimilation rate. Moreover, investigation of the relationship between $g_{\mathrm{s}}$ and the $\mathrm{CO}_{2}$ assimilation rate did not show a decrease in the $\mathrm{CO}_{2}$ assimilation rate independent of the change in $g_{s}$ (Supplementary Fig. S4). These considerations reconciled the cause of the decrease in $\mathrm{CO}_{2}$ assimilation as decrease in $g_{s}$, and Rubisco is protected from excess $M n$ in chloroplasts. To protect chloroplasts from excess free $\mathrm{Mn}$ accumulation, the homeostatic function of $\mathrm{Mn}^{2+}$ in the chloroplasts should function. At this point, two mechanisms can be considered. The first mechanism is binding Mn to the thylakoid membranes. Although this modulates membrane structure of the thylakoid membranes, no inhibitory effect on photosynthetic activity was observed (Lidon and Teixeira, 2000a, b). The binding of Mn to the thylakoid membrane could be a storage system for Mn homeostasis. The second mechanism is the sequestration or limiting Mn transport within chloroplasts. Indeed, Mn distributed to the chloroplasts was decreased under Mn-toxic conditions in rice (Führs et al., 2010). These homeostatic systems would prevent the deleterious effects of $\mathrm{Mn}^{2+}$ within the chloroplasts.

\section{Carbon catabolism due to reduced carbohydrates suppresses growth}


701 A decrease in respiration rate under Mn toxicity has been reported in wheat and cotton 702 plants (Sirkar and Amin, 1974; Macfie and Taylor, 1992). We also observed a decrease in 703 leaf respiration, but not in sucrose feeding (Fig. 5). Moreover, no decreases in mitochondrial 704 enzyme activities, including TCA cycle and respiratory electron transport chain enzymes, 705 were observed, except for the NAD-malic enzyme (Fig. 5). The physiological importance of 706 the NAD-malic enzyme is highly limited in C3 plants, and a pronounced phenotype has not 707 been observed in NAD-malic enzyme mutants in Arabidopsis (Tronconi et al., 2008). This 708 could be because of the lower contribution to the supply of pyruvate into the TCA cycle by 709 NAD-malic enzyme activity (Williams et al., 2008). These observations suggested that the 710 significant decrease in NAD-malic enzyme activity could be independent of the growth 711 defect and decreased respiration rate under Mn-toxic conditions (Figs. 1, 5). However, the 712 change in amino acid composition could be influenced by a decrease in the NAD-malic enzyme (Tronconi et al., 2008). From these observations, the decreased respiration rate was

714 caused by a decrease in carbohydrate concentrations due to the suppression of 715 photosynthesis (Sulpice et al., 2014). Carbohydrate catabolism during the night is a 716 determinant of plant growth (Takagi et al., 2016a). We suggest that a decrease in the 717 capacity of carbon catabolism causes growth defects in rice under Mn toxicity. Interestingly, 718 Hibberd and Quick (2002) reported that similar to C4 plants, the NAD-malic enzyme activity 719 is high in the bundle-sheath cells in C3 plants. Here, we found that the bundle-sheath cells 720 turned brown under Mn-toxic conditions (Fig. 7B, C). Based on a previous study on 721 apoplastic Mn toxicity, brown spots contained oxidised phenol, oxidised Mn, and callose. 722 Fernando et al. (2016) showed that wheat leaves concentrate $\mathrm{Mn}$ in the bundle-sheath cell. 723 However, this specific localisation was not observed in soybean and canola, suggesting that 724 the bundle-sheath cell could function as storage organs for attenuating $\mathrm{Mn}$ toxicity in 725 monocots. The Mn accumulation in the bundle sheath cell could cause the suppression of 726 the NAD-malic enzyme activity in leaves. These results provide insight for elucidating the 727 function of bundle-sheath cells in C3 monocots. 


\section{CONCLUDING REMARKS}

730 We proposed that the disturbance of IAA homeostasis is an initial cause of the inhibition of

$731 \quad \mathrm{CO}_{2}$ assimilation and photoinhibition caused chlorosis in the leaves (Fig. 9). As a short-term

732 effect, the decrease in IAA suppresses stomatal opening. Subsequently, the decrease in IAA

733 concentration modifies leaf anatomy and stomatal development in newly emerged leaves as

734 a long-term effect. Because leaf anatomy determines the $\mathrm{CO}_{2}$ pathway for efficient $\mathrm{CO}_{2}$

735 absorption by the chloroplasts, the lower internal air space could further lower the $\mathrm{CO}_{2}$

736 fixation efficiency under $\mathrm{Mn}$ toxicity (Earles et al., 2018). The decreased $\mathrm{CO}_{2}$ assimilation

737 rate and increased photorespiration rate decelerate carbon acquisition for catabolism; thus,

738 vegetative growth is suppressed. To our knowledge, there are limited studies focusing on

739 the relationship between auxins and Mn toxicity (Morgan et al., 1966). Tsunemitsu et al.

740 (2018) reported that the osmtp11 mutant decreased grain fertility and yield in rice. OsMTP11

741 undertakes $\mathrm{Mn}$ sequestration to the endoplasmic reticulum and is highly expressed in

742 inflorescences, including the anthers, pistil, lemmas, paleas, and ovaries (Tsunemitsu et al.,

743 2018). Together with our conclusion, Mn toxicity may also affect grain fertilisation by

744 disturbing IAA homeostasis. Not only the photosynthetic measurements but also the

745 developmental analyses from leaf emergence to the reproductive phase would provide more

746 insights into the mechanisms of the symplastic Mn-toxicity by focusing on IAA. 


\section{SUPPLEMENTARY DATA}

759 Figure S1; The sucrose-feeding respiration activities and mitochondrial respiratory electron

760 transport activities depending on ATP synthase (uncoupled), COX, and AOX based on leaf

761 fresh weight

762

763 Figure S2; The enzyme activities involved in the TCA cycle calculated on the fresh weight 764 basis.

765

Figure S3; The simulated $\mathrm{CO}_{2}$ assimilation in leaves containing Mg-binding Rubisco and Mn-binding Rubisco.

768

769

Figure S4; The relationship between $g_{s}$ and $\mathrm{CO}_{2}$ fixation rate under the control and the Mn-toxic conditions.

771

Table S1; The primer list for the gene expression analysis in rice leaf blade

Table S2; $\mathrm{Mg}^{2+}$-binding Rubisco and $\mathrm{Mn}^{2+}$-binding Rubisco kinetics. 


\section{ACKNOWLEDGEMENTS}

786 The authors thank Editage (https://www.editage.jp) for English language editing of the 787 manuscript. The authors also thank Prof. Yukio Ishikawa, Prof. Yutaka Okumoto, Prof.

788 Takeo Yamakawa, and Associate Prof. Shuji Sano at Setsunan University for their kind

789 technical support of this study. This work was supported by the Japan Society for the

790 Promotion of Science (JSPS) research fellowship (JSPS KAKENHI Grant No. 18J00852

791 [DT] and KAKENHI Grant No.16H06379 [AM]).

792

793 Conflicts of interest:

794 The authors declare no conflicts of interest.

795

796

\section{Author contributions:}

797 Conceptualisation: DT; investigation: DT, KI, MS, TU, TF, YT, MK, and KO; original draft: DT;

798 writing, review, and editing: DT, KI, MS, TU, TF, YT, MK, KO and AM; funding acquisition: DT 799 and AM.

\section{Data availability statements}

802 All data supporting the findings of this study are available within the article and its 803 supplementary figures and tables published online. 


\section{REFERENCES}

814 Andresen E, Peiter E, Küpper H. 2018. Trace metal metabolism in plants. Journal of

815 Experimental Botany 69, 909-954.

816

817 Araújo WL, Nunes-Nesi A, Osorio S, et al. 2011. Antisense inhibition of the iron-sulphur 818 subunit of succinate dehydrogenase enhances photosynthesis and growth in tomato via an 819 organic acid-mediated effect on stomatal aperture. The Plant Cell 23, 600-627.

Baker NR. 2008. Chlorophyll fluorescence: a probe of photosynthesis in vivo. Annual Review of Plant Biology 59, 89-113.

823

Balcerowicz M, Hoecker U. 2014. Auxin-a novel regulator of stomata differentiation. Trends in Plant Science 19, 747-749.

826

Blamey FPC, Joyce DC, Edwards DG, Asher CJ. 1986. Role of trichomes in sunflower tolerance to manganese toxicity. Plant and Soil $91,171-180$.

829

Blamey FPC, Hernandez-Soriano MC, Cheng M, Tang C, Paterson DJ, Lombi E, Wang WH, Scheckel KG, Kopittke PM. 2015. Synchrotron-based techniques shed light on mechanisms of 832 plant sensitivity and tolerance to high manganese in the root environment. Plant Physiology 169, 2006-2020.

Bloom AJ, Kameritsch P. 2017. Relative association of Rubisco with manganese and magnesium as a regulatory mechanism in plants. Physiologia Plantarum 161, 545-559.

Brestic M, Zivcak M, Kunderlikova K, Sytar O, Shao H, Kalaji HM, Allakhverdiev SI. 2015.

839 Low PSI content limits the photoprotection of PSI and PSII in early growth stages of chlorophyll b-deficient wheat mutant lines. Photosynthesis Research 125, 151-166. 
842 Broadley M, Brown P, Cakmak I, Rengel Z, Zhao F. 2012. Function of nutrients: micronutrients.

843 In Marschner's mineral nutrition of higher plants (eds Marschner, P.), pp. 135-189. Academic

844 Press, London.

845

846 Chatterjee C, Nautiyal N, Agarwala SC. 1994. Influence of changes in manganese and 847 magnesium supply on some aspects of wheat physiology. Soil Science and Plant Nutrition 40, 191-197.

849

Chen Z, Fujii Y, Yamaji N, et al. 2013. Mn tolerance in rice is mediated by MTP8. 1, a member of the cation diffusion facilitator family. Journal of Experimental Botany 64, 4375-4387.

852

Clairmont KB, Hagar WG, Davis EA. 1986. Manganese toxicity to chlorophyll synthesis in tobacco callus. Plant Physiology 80, 291-293.

855

Delhaize E, Kataoka T, Hebb DM, White RG, Ryan PR. 2003. Genes encoding proteins of the cation diffusion facilitator family that confer manganese tolerance. The Plant Cell 15, 1131-1142.

Du H, Wu N, Fu J, Wang S, Li X, Xiao J, Xiong L. 2012. A GH3 family member, OsGH3-2, modulates auxin and abscisic acid levels and differentially affects drought and cold tolerance in rice. Journal of Experimental Botany 63, 6467-6480.

862

Earles JM, Theroux-Rancourt G, Roddy AB, Gilbert ME, McElrone AJ, Brodersen CR. 2018.

Beyond porosity: 3D leaf intercellular airspace traits that impact mesophyll conductance. Plant Physiology 178, 148-162.

866 determines tolerance to iron deficiency-induced chlorosis in Arabidopsis. Plant Physiology 170, 
1030-1045.

870

871

872

873

874

875

876

877

878

879

881

882

883

885

886

887

888

889

890

891

892

893

894

895

896 237-244.

Fageria NK, Stone LF. 2008. Micronutrient deficiency problems in South America. In Micronutrient deficiencies in global crop production (pp. 245-266). Springer, Dordrecht.

Fecht-Christoffers MM, Braun HP, Lemaitre-Guillier C, VanDorsselaer A, Horst WJ. 2003a. Effect of manganese toxicity on the proteome of the leaf apoplast in cowpea. Plant Physiology 133, 1935-1946.

Fecht-Christoffers MM, Führs H, Braun HP, Horst WJ. 2006. The role of hydrogen peroxide-producing and hydrogen peroxide-consuming peroxidases in the leaf apoplast of cowpea in manganese tolerance. Plant Physiology 140, 1451-1463.

Fecht-Christoffers MM, Maier P, Horst WJ. 2003b. Apoplastic peroxidases and ascorbate are involved in manganese toxicity and tolerance of Vigna unguiculata. Physiologia Plantarum 117,

Fernando DR, Bakkaus EJ, Perrier N, Baker AJM, Woodrow IE, Batianoff GN, Collins RN. 2006. Manganese accumulation in the leaf mesophyll of four tree species: a PIXE/EDAX localization study. New Phytologist 171, 751-758.

Fernando DR, Lynch JP. 2015. Manganese phytotoxicity: new light on an old problem. Annals of Botany 116, 313-319.

Fernando DR, Moroni SJ, Scott BJ, Conyers MK, Lynch J, Marshall AT. 2016. Temperature and light drive manganese accumulation and stress in crops across three major plant families. Environmental and Experimental Botany 132, 66-79. 
897 Foy CD, Chaney RT, White MC. 1978. The physiology of metal toxicity in plants. Annual Review

898 of Plant Physiology 29, 511-566.

899

900 Franks PJ, Beerling DJ. 2009. Maximum leaf conductance driven by CO2 effects on stomatal

901 size and density over geologic time. Proceedings of the National Academy of Sciences 106,

$902 \quad 10343-10347$.

903

Führs H, Behrens C, Gallien S, Heintz D, Van Dorsselaer A, Braun HP, Horst WJ. 2010.

Physiological and proteomic characterization of manganese sensitivity and tolerance in rice (Oryza sativa) in comparison with barley (Hordeum vulgare). Annals of Botany 105, 1129-1140.

907

Führs H, Götze S, Specht A, Erban A, Gallien S, Heintz D, Van Dorsselaer A, Kopka J,

Braun H-P, Horst WJ. 2009. Characterization of leaf apoplastic peroxidases and metabolites in Vigna unguiculata in response to toxic manganese supply and silicon. Journal of Experimental Botany 60, 1663-1678.

912

Fujii T, Nakano R, Takubo Y, Qian S, Yamakawa R, Ando T, Ishikawa Y. 2010. Female sex pheromone of a lichen moth Eilema japonica (Arctiidae, Lithosiinae): components and control of production. Journal of Insect Physiology 56, 1986-1991.

916

González A, Lynch JP 1997. Effects of manganese toxicity on leaf $\mathrm{CO}_{2}$ assimilation of contrasting common bean genotypes. Physiologia Plantarum 101, 872-880.

919

González A, Steffen K., Lynch JP 1998. Light and excess manganese: implications for oxidative stress in common bean. Plant Physiology 118, 493-504.

922

923 Gutierrez CK, Matsui GY, Lincoln DE, Lovell CR. 2009. Production of the phytohormone 924 indole-3-acetic acid by estuarine species of the genus Vibrio. Applied and Environmental 
926

927

928

929

930

931

932

933

934

935

936

937

938

939

940

941

942

943

944

945

946

947

948

952

Microbiology 75, 2253-2258.

Guo X, Lu W, Ma Y, Qin Q, Hou S. 2013. The BIG gene is required for auxin-mediated organ growth in Arabidopsis. Planta 237, 1135-1147.

Hachiya T, Watanabe CK, Boom C, Tholen D, Takahara K, Kawai-Yamada M, Uchimiya H, Uesono Y, Terashima I. Noguchi K. 2010. Ammonium - dependent respiratory increase is dependent on the cytochrome pathway in Arabidopsis thaliana shoots. Plant, Cell \& Environment 33, 1888-1897.

Hibberd JM, Quick WP. 2002. Characteristics of C4 photosynthesis in stems and petioles of C3 flowering plants. Nature 415, 451-454.

Hirschi KD, Korenkov VD, Wilganowski NL, Wagner GJ. 2000. Expression of Arabidopsis CAX2 in tobacco. Altered metal accumulation and increased manganese tolerance. Plant Physiology 124, 125-134.

Horiguchi T. 1987. Mechanism of manganese toxicity and tolerance of plants: II. Deposition of oxidized manganese in plant tissues. Soil Science and Plant Nutrition 33, 595-606.

Horst WJ, Fecht M, Naumann A, Wissemeier AH, Maier P. 1999. Physiology of manganese toxicity and tolerance in Vigna unguiculata (L.) Walp. Journal of Plant Nutrition and Soil Science 162, 263-274.

Houtz RL, Nable RO, Cheniae GM. 1988. Evidence for effects on the in vivo activity of ribulose-bisphosphate carboxylase/oxygenase during development of $\mathrm{Mn}$ toxicity in tobacco. Plant Physiology 86, 1143-1149. 
959

960

961

962

963

964

965

Jain M, Kaur N, Garg R, Thakur JK, Tyagi AK, Khurana JP. 2006. Structure and expression analysis of early auxin-responsive Aux/IAA gene family in rice (Oryza sativa). Functional \& Integrative Genomics 6, 47-59.

Jezek M, Blatt MR. 2017. The membrane transport system of the guard cell and its integration for stomatal dynamics. Plant Physiology 174, 487-519.

Jordan DB, Ogren WL. 1983. Species variation in kinetic properties of ribulose 1, 5-bisphosphate carboxylase/oxygenase. Archives of Biochemistry and Biophysics 227, 425-433.

Kenten RH, Mann PJG. 1957. Manganese oxidation in the pea plant (Pisum sativum L.) grown under conditions of manganese toxicity. Biochemical Journal 65, 179-185.

Kitao M, Lei TT, Koike T. 1997. Effects of manganese toxicity on photosynthesis of white birch (Betula platyphylla var. japonica) seedlings. Physiologia Plantarum 101, 249-256.

Klein M, Perfus-Barbeoch L, Frelet A, Gaedeke N, Reinhardt D, Mueller-Roeber B, Martinoia E, Forestier C. 2003. The plant multidrug resistance ABC transporter AtMRP5 is involved in guard cell hormonal signalling and water use. The Plant Journal 33, 119-129.

Klughammer C, Schreiber U. 1994. Saturation pulse method for assessment of energy conversion in PS I. Planta 192, 261-268.

Kramer DM, Sacksteder CA, Cruz JA. 1999. How acidic is the lumen?. Photosynthesis Research 60, 151-163.

Lagrimini LM, Joly RJ, Dunlap JR, Liu TTY. 1997a. The consequence of peroxidase overexpression in transgenic plants on root growth and development. Plant Molecular Biology 33, 
887-895.

982

Lagrimini LM, Gingas V, Finger F, Rothstein S, Liu TTY. 1997b. Characterization of antisense transformed plants deficient in the tobacco anionic peroxidase. Plant Physiology 114, 1187-1196.

Le J, Liu XG, Yang KZ, et al. (2014). Auxin transport and activity regulate stomatal patterning and development. Nature Communications 5, 1-8.

Lei Y, Korpelainen H, Li C. 2007. Physiological and biochemical responses to high $\mathrm{Mn}$ concentrations in two contrasting Populus cathayana populations. Chemosphere 68, 686-694.

Li J, Jia Y, Dong R, Huang R, Liu P, Li X, Wang X, Liu G, Chen Z. 2019. Advances in the mechanisms of plant tolerance to manganese toxicity. International Journal of Molecular Sciences 20, 5096.

Lidon FC. 2002. Rice plant structural changes by addition of excess manganese. Journal of Plant Nutrition 25, 287-296.

Lidon FC, Barreiro MG, Ramalho JC. 2004. Manganese accumulation in rice: implications for photosynthetic functioning. Journal of Plant Physiology 161, 1235-1244.

Lidon FC, Teixeira MG. 2000a. Oxy radicals production and control in the chloroplast of Mn-treated rice. Plant Science 152, 7-15.

Lidon FC, Teixeira MG. 2000b. Rice tolerance to excess Mn: implications in the chloroplast lamellae and synthesis of a novel Mn protein. Plant Physiology and Biochemistry 38, 969-978.

Ljung K, Hull AK, Celenza J, Yamada M, Estelle M, Normanly J, Sandberg G. 2005. Sites 
1009 and regulation of auxin biosynthesis in Arabidopsis roots. The Plant Cell 17, 1090-1104.

1010

1011 Macfie SM, Taylor GJ. 1992. The effects of excess manganese on photosynthetic rate and 1012 concentration of chlorophyll in Triticum aestivum grown in solution culture. Physiologia 1013 Plantarum 85, 467-475.

1014

1015 Makino A, Mae T, Ohira K. 1988. Differences between wheat and rice in the enzymic properties 1016 of ribulose-1,5-bisphosphate carboxylase/oxygenase and the relationship to photosynthetic gas 1017 exchange. Planta, 174, 30-38.

1018

Makino A, Nakano H, Mae T. 1994. Responses of ribulose-1,5-bisphosphate carboxylase, 1020 cytochrome $f$, and sucrose synthesis enzymes in rice leaves to leaf nitrogen and their 1021 relationships to photosynthesis. Plant Physiology 105, 173-179.

1022

1023 McDaniel KL, Toman FR. 1994. Short - term effects of manganese toxicity on ribulose 1, 5 1024 bisphosphate carboxylase in tobacco chloroplasts. Journal of Plant Nutrition 17, 523-536.

1025

1026 McHargue JS. 1922. The role of manganese in plants. Journal of the American Chemical 1027 Society $44,1592-1598$.

1028

1029 Millaleo R, Reyes-Díaz M, Alberdi M, Ivanov AG, Krol M, Hüner NPA. 2013. Excess 1030 manganese differentially inhibits photosystem I versus II in Arabidopsis thaliana. Journal of 1031 Experimental Botany 64, 343-354.

1032

1033 Millaleo R, Reyes-Díaz M, Ivanov AG, Mora ML, Alberdi M. 2010. Manganese as essential 1034 and toxic element for plants: transport, accumulation and resistance mechanisms. Journal of Soil 1035 Science and Plant Nutrition 10, 470-481.

1036 
1037 Moraes TA, Mengin V, Annunziata MG, Encke B, Krohn N, Hoehne M, Stitt M. 2019.

1038 Response of the circadian clock and diel starch turnover to one day of low light or low $\mathrm{CO}_{2}$. Plant

1039 Physiology 179, 1457-1478.

1040

1041 Morgan PW, Joham HE, Amin JV. 1966. Effect of manganese toxicity on the indoleacetic acid 1042 oxidase system of cotton. Plant Physiology 41, 718-724.

1043

1044

Morita R, Sugino M, Hatanaka T, Misoo S, Fukayama H. 2015. $\mathrm{CO}_{2}$-responsive CONSTANS,

1045 CONSTANS-like, and time of chlorophyll a/b binding protein Expression1 protein is a positive

1046 regulator of starch synthesis in vegetative organs of rice. Plant Physiology 167, 1321-1331.

1047

1048 Muñoz-Nortes T, Pérez-Pérez JM, Ponce MR, Candela H, Micol JL. 2017. The ANGULATA 7

1049 gene encodes a DnaJ - like zinc finger - domain protein involved in chloroplast function and leaf

1050 development in Arabidopsis. The Plant Journal 89, 870-884.

1051

1052 Nable RO, Houtz RL, Cheniae GM. 1988. Early inhibition of photosynthesis during development

1053 of Mn toxicity in tobacco. Plant Physiology 86, 1136-1142.

1054

1055

Nakano H, Makino A, Mae T. 1997. The effect of elevated partial pressures of $\mathrm{CO}_{2}$ on the

1056 relationship between photosynthetic capacity and N content in rice leaves. Plant Physiology 115,

1057 191-198.

1058

1059

Nghi KN, Tagliani A, Mariotti L, Weits DA, Perata P, Pucciariello C. 2021. Auxin is required

1060 for the long coleoptile trait in japonica rice under submergence. New Phytologist 229, 85-93.

1061

1062 Noguchi Ko, Terashima I. 2006. Responses of spinach leaf mitochondria to low N 1063 availability. Plant, Cell \& Environment 29, 710-719. 
1065 Panda S, Mishra AK, Biswal UC. 1987. Manganese induced peroxidation of thylakoid lipids and

1066 changes in chlorophyll-a fluorescence during aging of cell free chloroplasts in

1067 light. Phytochemistry 26, 3217-3219.

1068

1069 Pérez-Pérez JM, Candela H, Robles P, López-Torrejón G, Del Pozo JC, Micol JL. 2010. A

1070 role for AUXIN RESISTANT3 in the coordination of leaf growth. Plant and Cell Physiology 51, $1071 \quad 1661-1673$.

1072

1073 Porra RJ, Thompson WA, Kriedemann PE. 1989. Determination of accurate extinction 1074 coefficients and simultaneous equations for assaying chlorophylls $a$ and $b$ extracted with four 1075 different solvents: verification of the concentration of chlorophyll standards by atomic absorption 1076 spectroscopy. Biochimica et Biophysica Acta-Bioenergetics 975, 1104 384-394.

1077

1078 Qi J, Wang Y, Yu T, Cunha A, Wu B, Vernoux T, Meyerowitz E, Jiao Y. 2014. Auxin depletion 1079 from leaf primordia contributes to organ patterning. Proceedings of the National Academy of 1080 Sciences 111, 18769-18774.

1081

1082 Ray PM. 1958. Destruction of auxin. Annual Review of Plant Physiology 9, 81-118.

1083

1084 Perrot-Rechenmann C. 2010. Cellular responses to auxin: division versus expansion. Cold 1085 Spring Harbor Perspectives in Biology 2, a001446.

1086

1087 Robert HS, Friml J. 2009. Auxin and other signals on the move in plants. Nature Chemical 1088 Biology 5, 325-332.

1089

1090 Santos EF, Santini JMK, Paixão AP, Júnior EF, Lavres J, Campos M, Dos Reis AR. 2017.

1091 Physiological highlights of manganese toxicity symptoms in soybean plants: Mn toxicity 1092 responses. Plant Physiology and Biochemistry 113, 6-19. 
1094 Sasaki A, Yamaji N, Xia J, Ma JF. 2011. OsYSL6 is involved in the detoxification of excess

1095 manganese in rice. Plant Physiology 157, 1832-1840.

1096

1097 Shao JF, Yamaji N, Shen RF, Ma JF. 2017. The key to Mn homeostasis in plants: regulation of 1098 Mn transporters. Trends in Plant Science 22, 215-224.

1099

1100 Sirkar S, Amin JV. 1974. The manganese toxicity of cotton. Plant Physiology 54, 539-543.

1101

1102 Suga M, Akita F, Hirata K, et al. 2015. Native structure of photosystem II at $1.95 \AA$ resolution 1103 viewed by femtosecond X-ray pulses. Nature 517, 99-103.

1104

1105 Suganami M, Suzuki Y, Tazoe Y, Yamori W, Makino A. 2021. Co-overproducing Rubisco 1106 and Rubisco activase enhances photosynthesis in the optimal temperature range in 1107 rice. Plant Physiology, 185, 108-119.

1109 Sulpice R, Flis A, Ivakov AA, Apelt F, Krohn N, Encke B, Abel C, Feil R, Lunn JE, Stitt M.

1110 2014. Arabidopsis coordinates the diurnal regulation of carbon allocation and growth across a

1111 wide range of photoperiods. Molecular Plant 7, 137-155.

1112

1113 Suresh R, Foy CD, Weidner JR. 1987. Effects of excess soil manganese on stomatal function in 1114 two soybean cultivars. Journal of Plant Nutrition 10, 749-760.

1116 Suzuki Y, Fujimori T, Kanno K, Sasaki A, Ohashi Y, Makino A. 2012. Metabolome analysis of 1117 photosynthesis and the related primary metabolites in the leaves of transgenic rice plants with 1118 increased or decreased Rubisco content. Plant, Cell \& Environment 35, 1369-1379.

1120 Suzuki Y, Kawazu T, Koyama H. 2004. RNA isolation from siliques, dry seeds and other 
1121 tissues of Arabidopsis thaliana. Biotechniques 37, 542-544.

1122

1123 Takagi D, Amako K, Hashiguchi M, et al. 2017. Chloroplastic ATP synthase builds up a proton

1124 motive force preventing production of reactive oxygen species in photosystem I. The Plant 1125 Journal 91, 306-324.

1126

1127 Takagi D, Hashiguchi M, Sejima T, Makino A, Miyake C. 2016b. Photorespiration provides the 1128 chance of cyclic electron flow to operate for the redox-regulation of P700 in photosynthetic 1129 electron transport system of sunflower leaves. Photosynthesis Research 129, 279-290.

1131 Takagi D, Ifuku K, Ikeda KI, Inoue KI, Park P, Tamoi M, Inoue H, Sakamoto K, Saito R, 1132 Miyake C. 2016a. Suppression of chloroplastic alkenal/one oxidoreductase represses the 1133 carbon catabolic pathway in Arabidopsis leaves during night. Plant Physiology 170, 2024-2039.

1135 Takagi D, Miyagi A, Tazoe Y, Suganami M, Kawai-Yamada M, Ueda A, Suzuki Y, Noguchi K, 1136 Hirotsu N, Makino A. 2020. Phosphorus toxicity disrupts Rubisco activation and reactive 1137 oxygen species defence systems by phytic acid accumulation in leaves. Plant, Cell \& 1138 Environment 43, 2033-2053.

1140 Takahama U. 2004. Oxidation of vacuolar and apoplastic phenolic substrates by peroxidase: 1141 physiological significance of the oxidation reactions. Phytochemistry Reviews 3, 207-219.

1143 Tognetti VB, Mühlenbock PER, Van Breusegem F. 2012. Stress homeostasis-the redox and 1144 auxin perspective. Plant, Cell \& Environment, 35, 321-333.

1146 Tsunemitsu Y, Genga M, Okada T, Yamaji N, Ma JF, Miyazaki A, Kato S, Iwasaki K, Ueno D. 1147 2018. A member of cation diffusion facilitator family, MTP11, is required for manganese tolerance 1148 and high fertility in rice. Planta 248, 231-241. 
1150 Tronconi MA, Fahnenstich H, Weehler MCG, Andreo CS, Flügge UI, Drincovich MF,

1151 Maurino VG. 2008. Arabidopsis NAD-malic enzyme functions as a homodimer and heterodimer

1152 and has a major impact on nocturnal metabolism. Plant Physiology 146, 1540-1552.

1153

Valdés-López O, Yang SS, Aparicio-Fabre R, Graham PH, Reyes JL, Vance CP, Hernández

G. 2010. MicroRNA expression profile in common bean (Phaseolus vulgaris) under nutrient

1156 deficiency stresses and manganese toxicity. New Phytologist 187, 805-818.

1157

1158 Vlamis J, Williams DE. 1964. Iron and manganese relations in rice and barley. Plant and Soil 20, $1159 \quad 221-231$.

1160

1161

von Caemmerer S, Farquhar GD. 1981. Some relationships between the biochemistry of

1162 photosynthesis and the gas exchange of leaves. Planta 153, 376-387

1163

1164 Wada S, Takagi D, Miyake C, Makino A, Suzuki Y. 2019. Responses of the photosynthetic

1165 electron transport reactions stimulate the oxidation of the reaction center chlorophyll of

1166 photosystem I, P700, under drought and high temperatures in rice. International Journal of

1167 Molecular Sciences 20, 2068.

1168

1169 Walle, F, Furuya M, Nick P. 2002. OsARF1, an auxin response factor from rice, is auxin-regulated and classifies as a primary auxin responsive gene. Plant Molecular Biology 50, 415-425.

1172

1173 Wang D, Pei K, Fu Y, Sun Z, Li S, Liu H, Tang K, Han B, Tao Y. 2007. Genome-wide analysis

1174 of the auxin response factors (ARF) gene family in rice (Oryza sativa). Gene 394, 13-24.

1175

1176 Williams TC, Miguet L, Masakapalli SK, Kruger NJ, Sweetlove LJ, Ratcliffe RG. 2008. 
1177 Metabolic network fluxes in heterotrophic Arabidopsis cells: stability of the flux distribution under

1178 different oxygenation conditions. Plant Physiology 148, 704-718.

1179

1180 Wissemeier AH, Horst WJ. 1987. Callose deposition in leaves of cowpea (Vigna unguiculata

1181 [L.] Walp.) as a sensitive response to high Mn supply. Plant and Soil 102, 283-286.

1182

1183 Wissemeier AH, Horst WJ. 1992. Effect of light intensity on manganese toxicity symptoms and

1184 callose formation in cowpea (Vigna unguiculata (L.) Walp.). Plant and Soil 143, 299-309.

1185

1186 Zhang JY, He SB, Li L, Yang HQ. 2014. Auxin inhibits stomatal development through

1187 MONOPTEROS repression of a mobile peptide gene STOMAGEN in mesophyll. Proceedings of

1188 the National Academy of Sciences 111, E3015-E3023.

1189

1190 Zhao Z, Zhang Y, Liu X, et al. 2013. A role for a dioxygenase in auxin metabolism and

1191 reproductive development in rice. Developmental Cell 27, 113-122.

1192

1193

Zivcak M, Brestic M, Balatova Z, Drevenakova P, Olsovska K, Kalaji HM, Yang X,

1194 Allakhverdiev SI. 2013. Photosynthetic electron transport and specific photoprotective

1195 responses in wheat leaves under drought stress. Photosynthesis Research 117, 529-546.

1196

1197

1198

1199

1200

1201

1202

1203

1204 


\section{FIGURE LEGENDS}

\section{$1206 \quad$ Figure 1}

1207 Phenotypes of rice plants grown under control and Mn-toxic conditions. The pictures of fully

1208 expanded leaf blades grown under control and Mn-toxic conditions are shown in (A), and (B) 1209 shows an enlarged picture of these. The white bars indicate lengths of $1 \mathrm{~cm}(\mathrm{~A})$ and $1 \mathrm{~mm}$

1210 (B), respectively. (C) The dried weights of the leaf blade, leaf sheath, and root, respectively.

1211 (D) The sum of the dried weights shown in (C). Data are shown as box plots $(n=9)$, black 1212 squares indicate the mean value, and bars indicate the range of the maximum or minimum 1213 data within a $1.5 \times$ interquartile range (IQR). Green boxes indicate the results of the control 1214 conditions, and red boxes indicate those of the Mn-toxic conditions. Asterisks show 1215 significant differences between the control and Mn-toxic conditions ( ${ }^{*}: p<0.05$, 1216 Kruskal-Wallis test).

\section{Figure 2}

1219 Mineral concentration in the rice leaf blade. Data are shown as box plots (control conditions $1220 \mathrm{n}=8$, Mn-toxic conditions $\mathrm{n}=7$ ), black squares indicate the mean value, and bars indicate 1221 the range of the maximum or minimum data within a $1.5 \times$ interquartile range (IQR). Green 1222 boxes indicate the results of the control conditions, and red boxes indicate those of the 1223 Mn-toxic conditions. Asterisks show significant differences between the control and Mn-toxic 1224 conditions $\left({ }^{*}: p<0.05,{ }^{* *}: p<0.01\right.$, Kruskal-Wallis test).

\section{Figure 3}

1227 Photosynthetic activities in leaves grown under control and the Mn-toxic conditions. The $1228 \mathrm{CO}_{2}$ assimilation rate $(\mathrm{A})$, stomatal conductance $\left(g_{s}\right)(\mathrm{B})$, and intercellular $\mathrm{CO}_{2}$ concentration 1229 (C) are shown. For the PSII photosynthetic parameters, the quantum yields of PSII [Y(II)] (D), 1230 non-photochemical quenching $[\mathrm{Y}(\mathrm{NPQ})](\mathrm{E})$, and non-radiative decay $[\mathrm{Y}(\mathrm{NO})](\mathrm{F})$ are shown. 1231 The maximum quantum yield of PSII (Fv/Fm) is shown (J). For PSI photosynthetic 1232 parameters, the quantum yields of $\mathrm{PSI}[\mathrm{Y}(\mathrm{I})](\mathrm{G})$, non-photochemical quenching at the donor 
1233 side $[\mathrm{Y}(\mathrm{ND})](\mathrm{H})$, and non-photochemical quenching at the acceptor side $[\mathrm{Y}(\mathrm{NA})](\mathrm{I})$ are

1234 shown. (K) and (L) show the total $\mathrm{Chl}$ and $\mathrm{N}$ concentrations in the leaves, respectively. Data

1235 of photosynthetic parameters are shown as means with standard deviation (SD) $(n=7)$. The

1236 results for Fv/Fm $(n=7)$ and total $\mathrm{Chl}(\mathrm{n}=7)$ and $\mathrm{N}(\mathrm{n}=9)$ concentrations are shown as box

1237 plots. Black squares indicate the mean value, and bars indicate the range of the maximum

1238 or minimum data within a $1.5 \times$ interquartile range (IQR). Asterisks show significant

1239 differences between the control and Mn-toxic conditions $\left({ }^{*}: p<0.05,{ }^{* *}: p<0.01\right.$,

1240 Kruskal-Wallis test).

1241

\section{$1242 \quad$ Figure 4}

1243 Carbohydrate content in leaf blades at the end of the day and end of the night. Data are

1244 shown as means with standard deviation (SD) $(n=3-4)$, and squares and diamonds show

1245 the distribution of the raw data. Asterisks show significant differences between the control

1246 and Mn-toxic conditions ( ${ }^{*}: p<0.05$, Kruskal-Wallis test).

1247

\section{$1248 \quad$ Figure 5}

1249 Mitochondrial respiration activities and amino acid contents in leaf blades grown under

1250 control and Mn-toxic conditions. (A) Leaf respiration rate $(n=12-13)$ in the dark and $(B)$

1251 sucrose feeding respiration activities and mitochondrial respiratory electron transport

1252 activities depending on ATP synthase (uncoupled), COX, and AOX ( $n=7)$. (C) Amino acid

1253 content in leaves sampled in the middle of the night $(n=6)$. (D-I) Enzyme activities involved

1254 in the TCA cycle $(n=13-14)$. Data are shown as box plots, black squares indicate the mean

1255 value, and bars indicate the range of the maximum or minimum data within a $1.5 \times$

1256 interquartile range (IQR). Green boxes indicate the results under control conditions, and red

1257 boxes indicate those under Mn-toxic conditions. Asterisks show significant differences

1258 between the control and Mn-toxic conditions $\left({ }^{*}: p<0.05,{ }^{* *}: p<0.01\right.$, Kruskal-Wallis test).

1259

$1260 \quad$ Figure 6 
1261 Stomatal structures and characteristics in the rice leaf blade. Pictures of the stomata on the

1262 adaxial side of the leaf blade grown under control (A) and Mn-toxic (B) conditions. The upper

1263 pictures focus on the stomatal distributions, and the lower pictures focus on the single

1264 stomata complex. (C) Showed the stomatal density $(n=10-12)$. (D) and (E) showed the

1265 major and the minor axis of the stomatal complex, respectively $(n=53-63)$. Data are shown

1266 as box plots, black squares indicate the mean value, and bars indicate the range of the 1267 maximum or minimum data within a $1.5 \times$ interquartile range (IQR). Green boxes indicate

1268 the results under control conditions, and red boxes indicate those under Mn-toxic conditions.

1269 Asterisks show significant differences between the control and Mn-toxic conditions $\left({ }^{*}: p<\right.$

$1270 \quad 0.05,{ }^{* * *}: p<0.001$, Kruskal-Wallis test).

1271

\section{$1272 \quad$ Figure 7}

1273 Characteristics of the leaf section grown under control and Mn-toxic conditions. (A) Fixed

1274 leaf sections sectioned from the horizontal and vertical side against the leaf vein. Fresh leaf

1275 sections of the small $(B)$ and large $(C)$ bundles. Black bars show the scales.

1276

$1277 \quad$ Figure 8

1278 Leaf indole acetic acid (IAA) concentration and gene expression analysis relating to IAA and

1279 stomata development. (A) The result of GC-MS analysis targeting IAA, together with the

1280 chemical structures of IAA and its derivatives. The total ion chromatography (TIC) and

1281 chromatographs of $m / z=202$ and $m / z=319$ in the standard IAA solution and the leaf extract

1282 from plants under control and Mn-toxic conditions are shown. The retention time of the

1283 silylated IAA was 15.2 min. (B) The IAA concentrations in the leaf blade ( $n=8)$. (D) The

1284 results of gene expression analysis involving IAA-responsive gene and stomatal patterning

$1285(\mathrm{n}=8)$. The quantified results are expressed on an OsATC1-2 expression basis. Asterisks

1286 show significant differences between the control and Mn-toxic conditions $\left({ }^{*}: p<0.05,{ }^{* *}: p<\right.$

$1287 \quad 0.01$, Kruskal-Wallis test). 


\section{Figure 9}

1290 Visual scheme of symplastic $\mathrm{Mn}$ toxicity to suppress $\mathrm{CO}_{2}$ assimilation. When $\mathrm{Mn}$ is

1291 excessively accumulated in leaves, the leaf IAA concentration is lowered, which might cause

1292 the stimulation of IAA degradation activities under Mn toxicity (Morgan et al., 1996). As a

1293 short-term effect, the decrease in IAA concentration affects stomatal opening (Blatt \& Thiel,

1294 1994; Klein et al., 2003). Subsequently, as a long-term effect, the auxin-dependent signal

1295 transduction involving ARF transcriptional factor is perturbated in the leaves to cause an

1296 IAA-deficient phenotype, changing both stomatal and leaf anatomical structures (Le et al.,

1297 2014; Zhang et al., 2014). The change in stomatal function and leaf structure severely limits

$1298 \mathrm{CO}_{2}$ diffusion to the chloroplasts, and $\mathrm{CO}_{2}$ assimilation by Rubisco is inhibited. In contrast,

1299 the photorespiration reaction limits the photosynthetic electron activities to cause ROS

1300 production (Wada et al., 2019). The decreased sugar production efficiency in

1301 photosynthesis suppresses sugar catabolism. Therefore, growth is inhibited under Mn-toxic

1302 conditions.

1303 
bioRxiv preprint doi: https://doi.org/10.1101/2021.03.16.435720; this version posted March 18, 2021. The copyright holder for this preprint (which was not certified by peer review) is the author/funder, who has granted bioRxiv a license to display the preprint in perpetuity. It is made available under aCC-BY-ND 4.0 International license.

A

The Control-Mn conditions

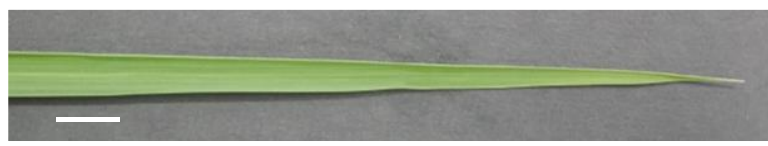

The Mn-toxic conditions

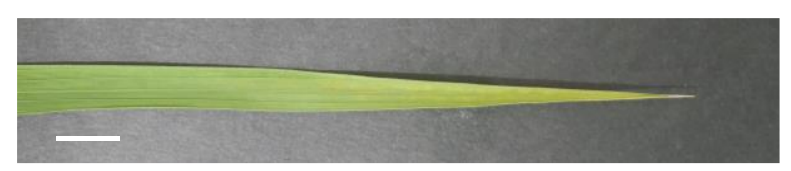

B

The Control-Mn conditions

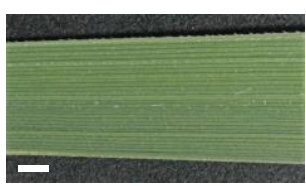

The Mn-toxic conditions

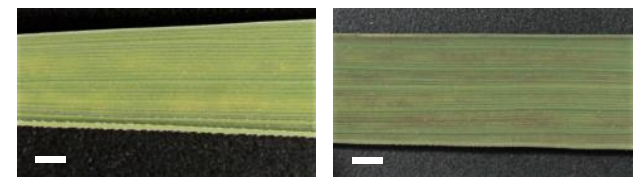

D
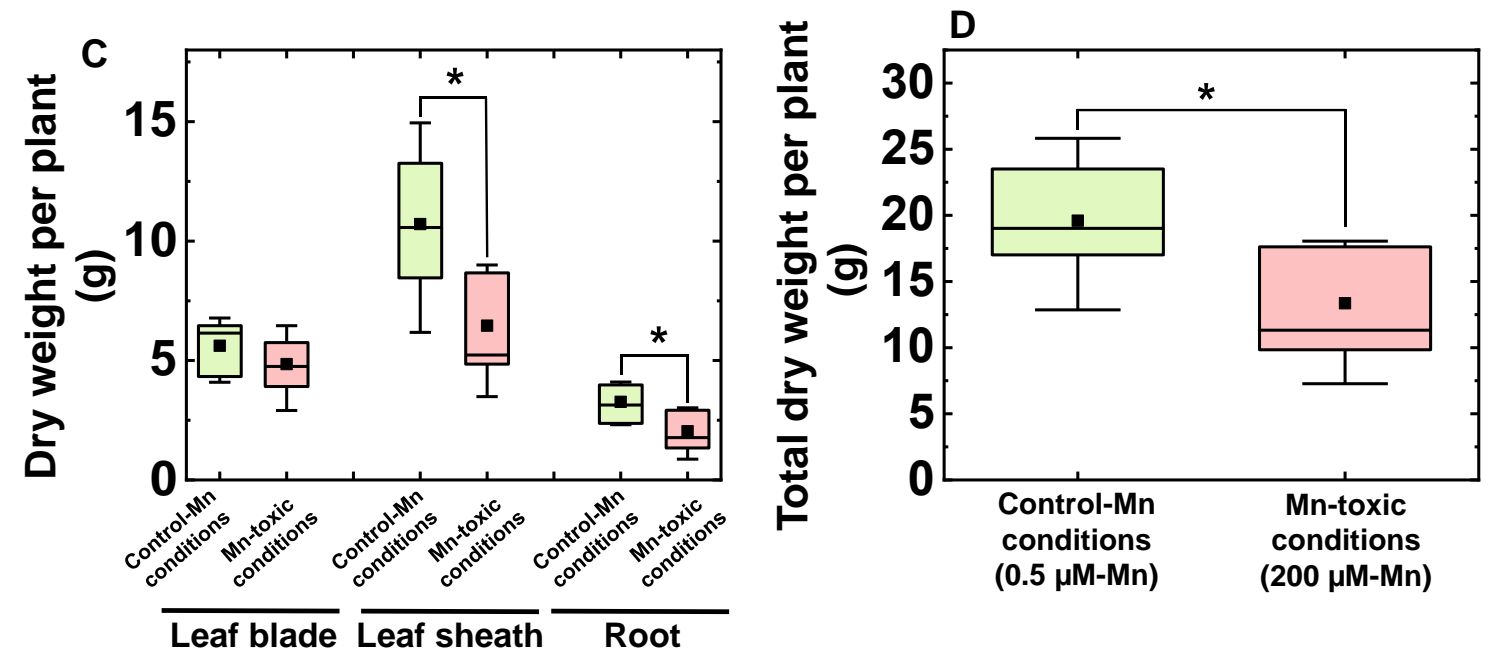

Figure 1

Phenotypes of rice plants grown under control and Mn-toxic conditions. The pictures of fully expanded leaf blades grown under control and Mn-toxic conditions are shown in (A), and (B) shows an enlarged picture of these. The white bars indicate lengths of $1 \mathrm{~cm}(A)$ and $1 \mathrm{~mm}$ (B), respectively. (C) The dried weights of the leaf blade, leaf sheath, and root, respectively. (D) The sum of the dried weights shown in (C). Data are shown as box plots $(n=9)$, black squares indicate the mean value, and bars indicate the range of the maximum or minimum data within a 1.5× interquartile range (IQR). Green boxes indicate the results of the control conditions, and red boxes indicate those of the Mn-toxic conditions. Asterisks show significant differences between the control and Mn-toxic conditions $\left(^{*}: p<0.05\right.$, KruskalWallis test). 

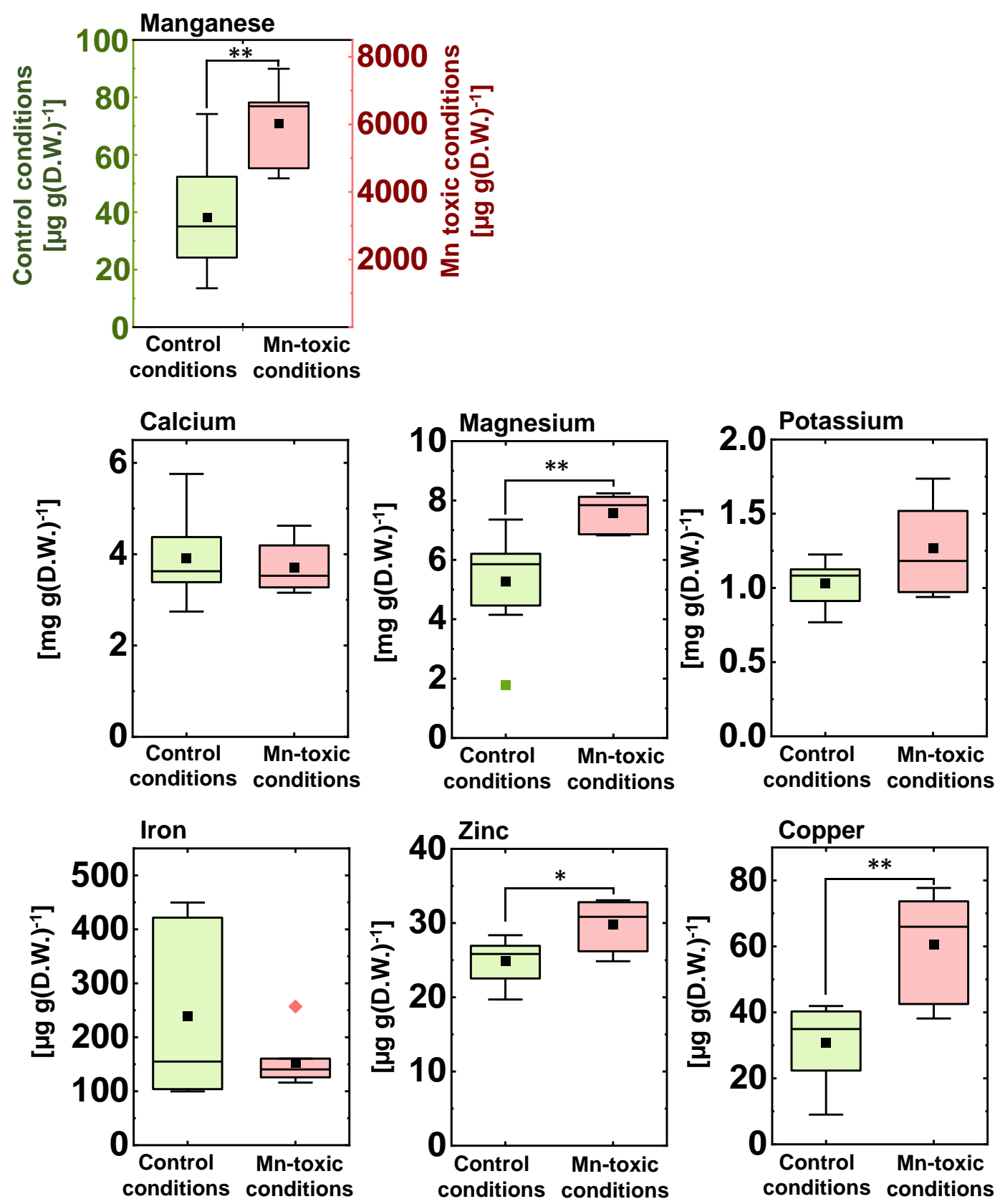

\section{Figure 2}

Mineral concentration in the rice leaf blade. Data are shown as box plots (control conditions $\mathrm{n}=8$, Mn-toxic conditions $\mathrm{n}=7$ ), black squares indicate the mean value, and bars indicate the range of the maximum or minimum data within a $1.5 \times$ interquartile range (IQR). Green boxes indicate the results of the control conditions, and red boxes indicate those of the $\mathrm{Mn}$ toxic conditions. Asterisks show significant differences between the control and Mn-toxic conditions $\left({ }^{*}: p<0.05,{ }^{* *}: p<0.01\right.$, Kruskal-Wallis test). 


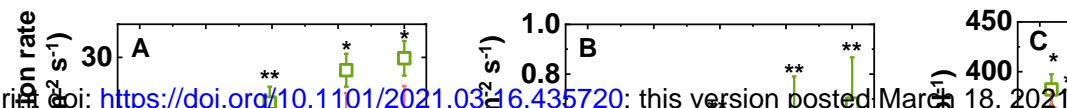

bioRxiv preprifำ (which was not s.
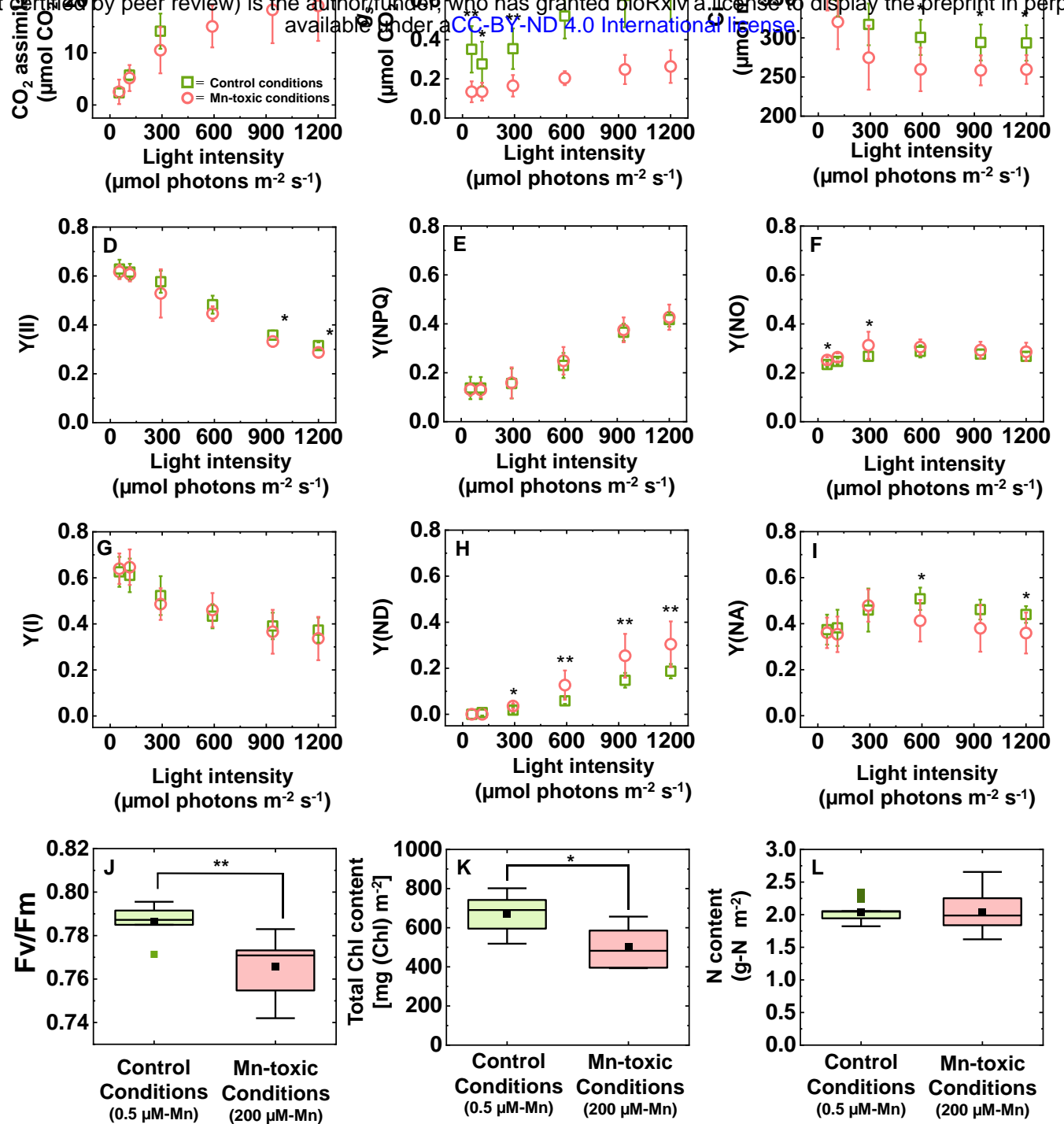

\section{Figure 3}

Photosynthetic activities in leaves grown under control and the Mn-toxic conditions. The $\mathrm{CO}_{2}$ assimilation rate $(A)$, stomatal conductance $\left(g_{s}\right)(B)$, and intercellular $\mathrm{CO}_{2}$ concentration $(C)$ are shown. For the PSII photosynthetic parameters, the quantum yields of PSII [Y(II)] (D), non-photochemical quenching $[\mathrm{Y}(\mathrm{NPQ})](\mathrm{E})$, and non-radiative decay $[\mathrm{Y}(\mathrm{NO})](\mathrm{F})$ are shown. The maximum quantum yield of PSII (Fv/Fm) is shown (J). For PSI photosynthetic parameters, the quantum yields of $P S I[Y(I)](G)$, non-photochemical quenching at the donor side $[Y(N D)](H)$, and non-photochemical quenching at the acceptor side $[Y(N A)](I)$ are shown. $(\mathrm{K})$ and $(\mathrm{L})$ show the total $\mathrm{Chl}$ and $\mathrm{N}$ concentrations in the leaves, respectively. Data of photosynthetic parameters are shown as means with standard deviation (SD) $(n=7)$. The results for Fv/Fm $(n=7)$ and total $C h l(n=7)$ and $N(n=9)$ concentrations are shown as box plots. Black squares indicate the mean value, and bars indicate the range of the maximum or minimum data within a $1.5 \times$ interquartile range (IQR). Asterisks show significant differences between the control and Mn-toxic conditions ( ${ }^{*}: p<0.05,{ }^{* *}: p<0.01$, KruskalWallis test). 

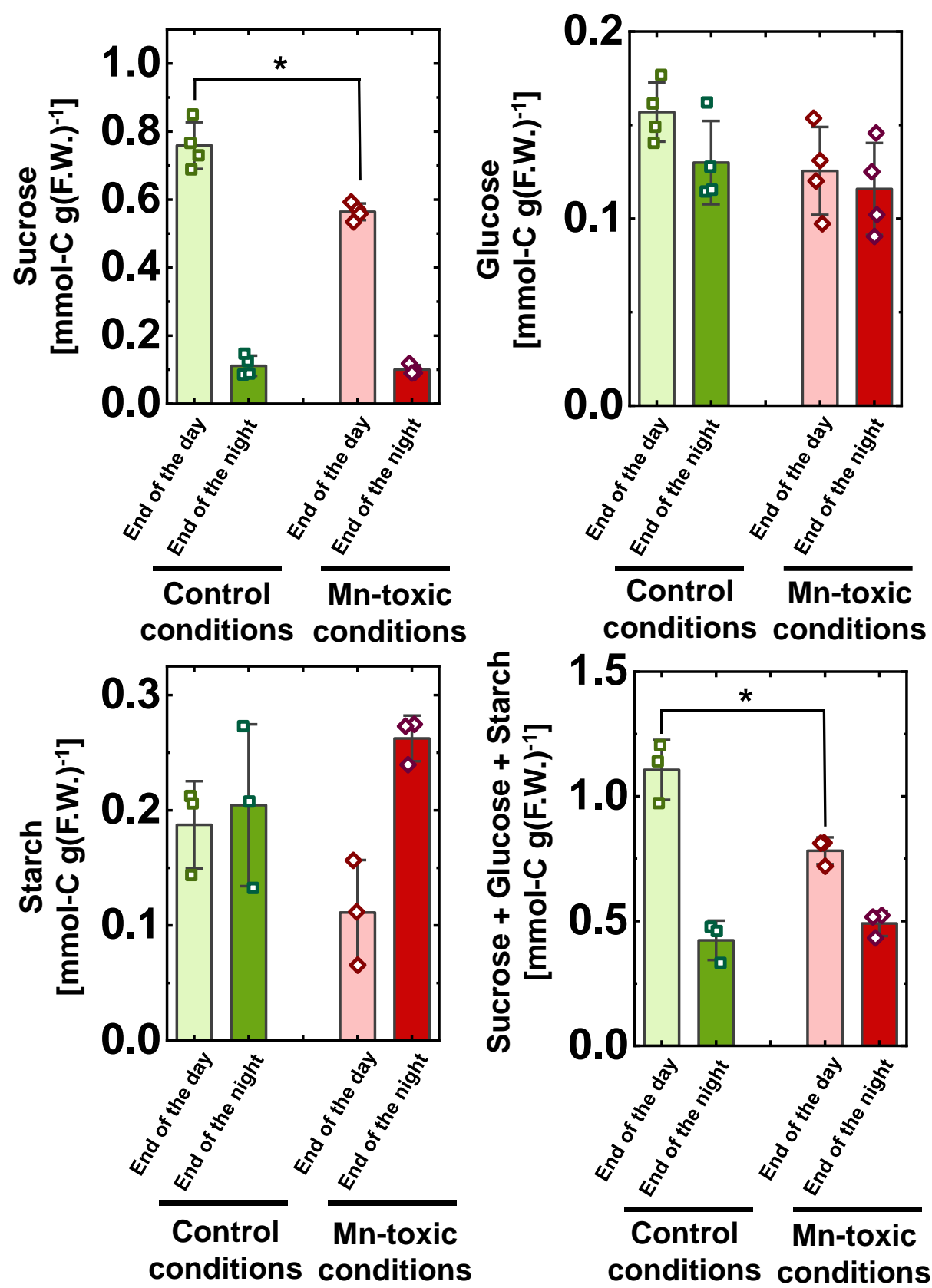

Figure 4

Carbohydrate content in leaf blades at the end of the day and end of the night. Data are shown as means with standard deviation (SD) $(n=3-4)$, and squares and diamonds show the distribution of the raw data. Asterisks show significant differences between the control and Mn-toxic conditions ( ${ }^{*}: p<0.05$, Kruskal-Wallis test). 


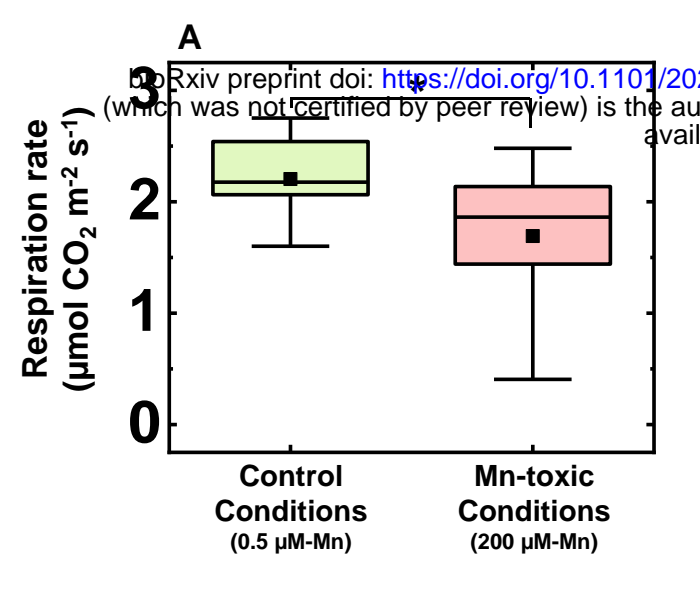

$80^{\mathrm{B}}$
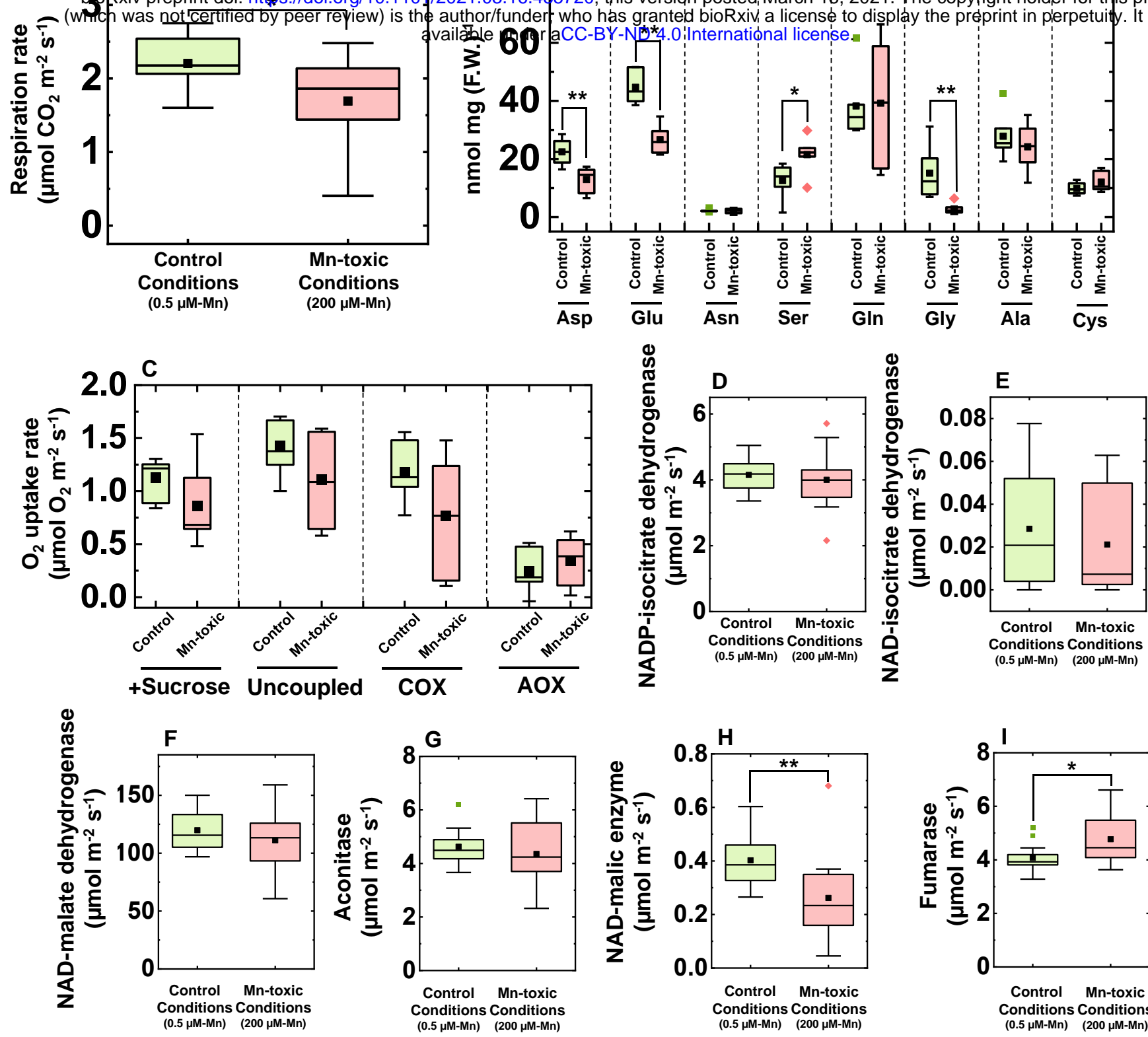

Figure 5
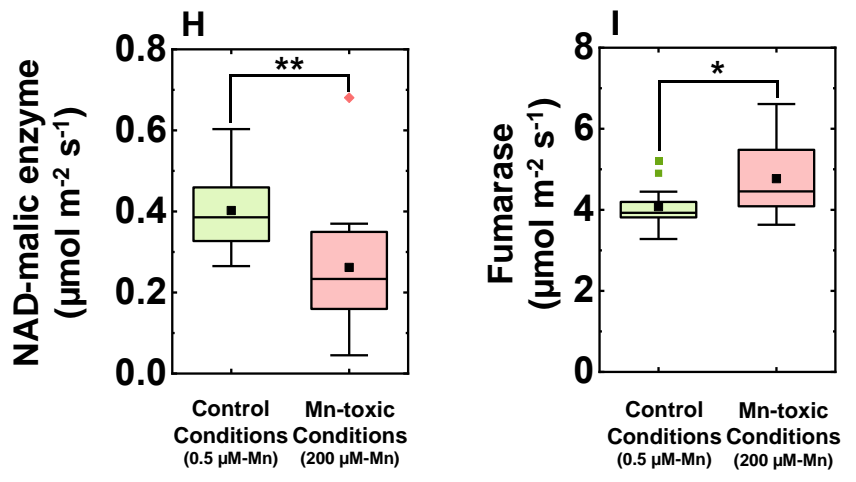

Mitochondrial respiration activities and amino acid contents in leaf blades grown under control and Mn-toxic conditions. (A) Leaf respiration rate $(n=12-13)$ in the dark and $(B)$ sucrose feeding respiration activities and mitochondrial respiratory electron transport activities depending on ATP synthase (uncoupled), COX, and AOX ( $n=7)$. (C) Amino acid content in leaves sampled in the middle of the night $(n=6)$. (D-l) Enzyme activities involved in the TCA cycle $(n=13-14)$. Data are shown as box plots, black squares indicate the mean value, and bars indicate the range of the maximum or minimum data within a $1.5 \times$ interquartile range (IQR). Green boxes indicate the results under control conditions, and red boxes indicate those under Mn-toxic conditions. Asterisks show significant differences between the control and Mn-toxic conditions ( ${ }^{*}: p<0.05,{ }^{* *}: p<0.01$, Kruskal-Wallis test). 

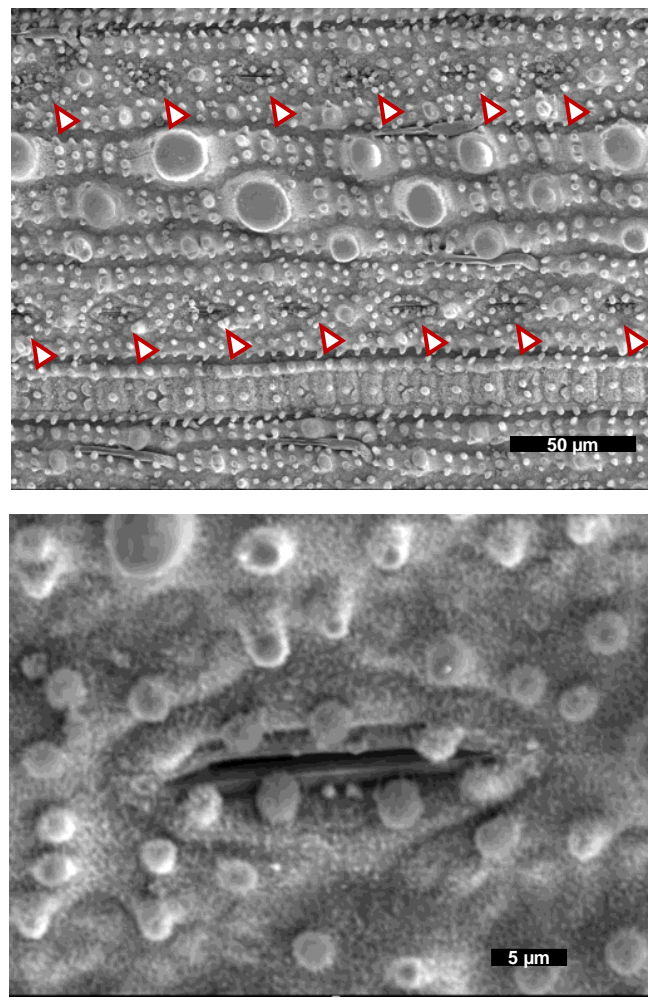
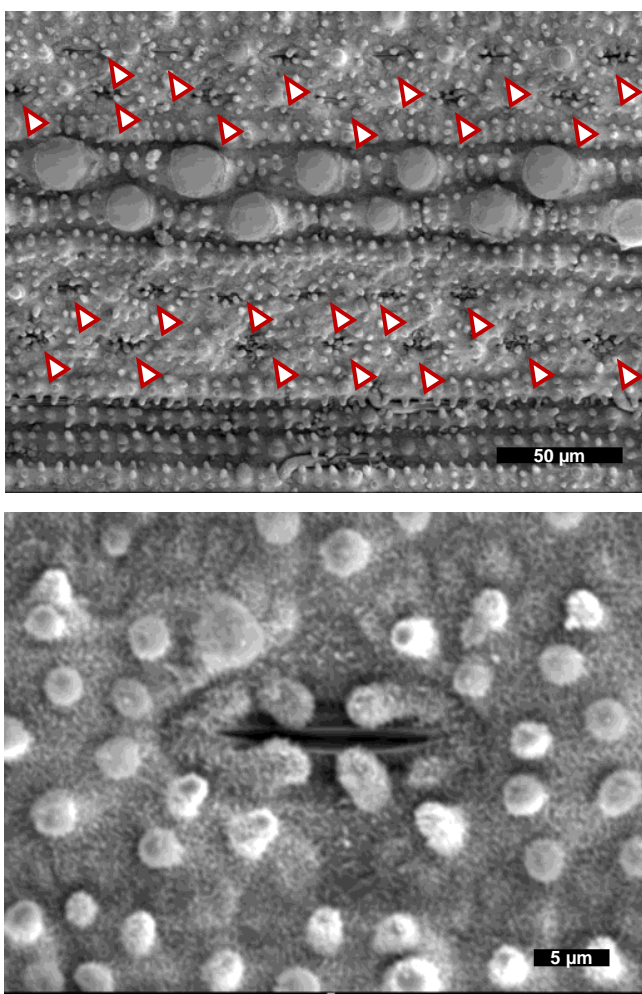
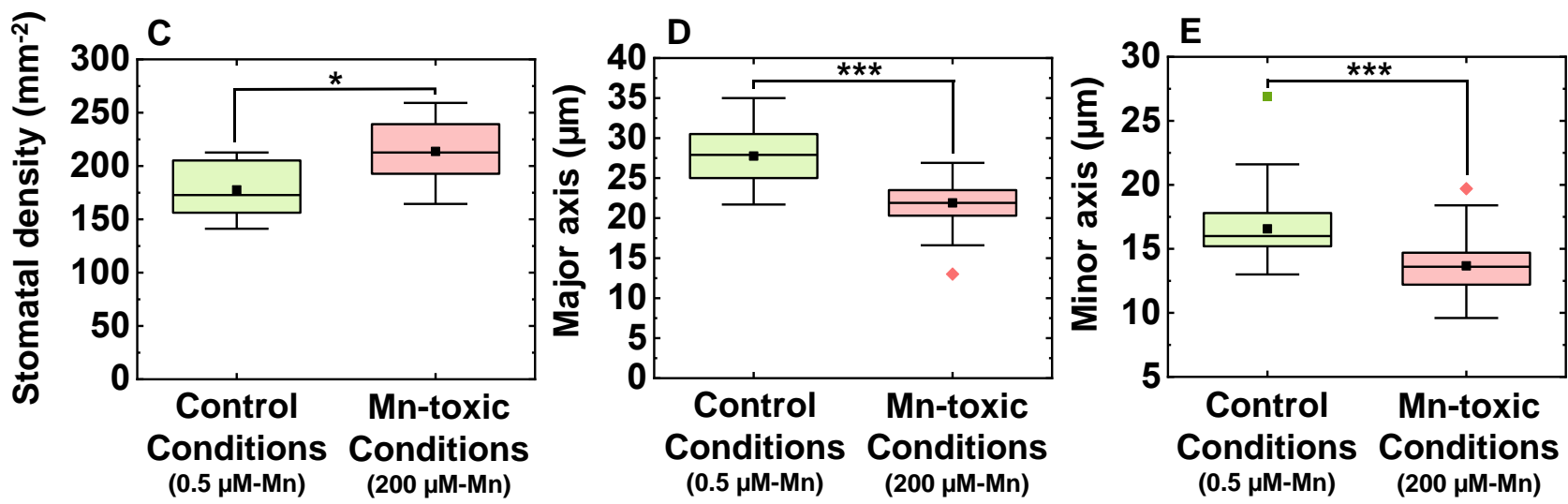

\section{Figure 6}

Stomatal structures and characteristics in the rice leaf blade. Pictures of the stomata on the adaxial side of the leaf blade grown under control $(A)$ and Mn-toxic $(B)$ conditions. The upper pictures focus on the stomatal distributions, and the lower pictures focus on the single stomata complex. (C) Showed the stomatal density $(n=10-12)$. (D) and (E) showed the major and the minor axis of the stomatal complex, respectively $(n=53-63)$. Data are shown as box plots, black squares indicate the mean value, and bars indicate the range of the maximum or minimum data within a $1.5 \times$ interquartile range (IQR). Green boxes indicate the results under control conditions, and red boxes indicate those under Mn-toxic conditions. Asterisks show significant differences between the control and Mn-toxic conditions ( ${ }^{*}: p<$ $0.05,{ }^{* * *}: p<0.001$, Kruskal-Wallis test). 
bioRxiv preprint doi: https://doi.org/10.1101/2021.03.16.435720; this version posted March 18, 2021. The copyright holder for this preprint (which was not certified by peer review) is the author/funder, who has granted bioRxiv a license to display the preprint in perpetuity. It is made available under aCC-BY-ND 4.0 International license.

A

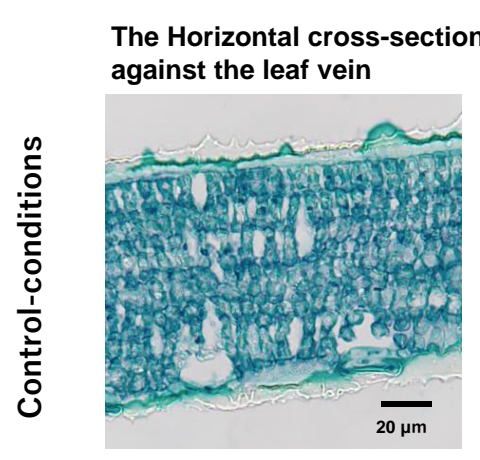

\author{
The Vertical cross-section \\ against the leaf vein
}
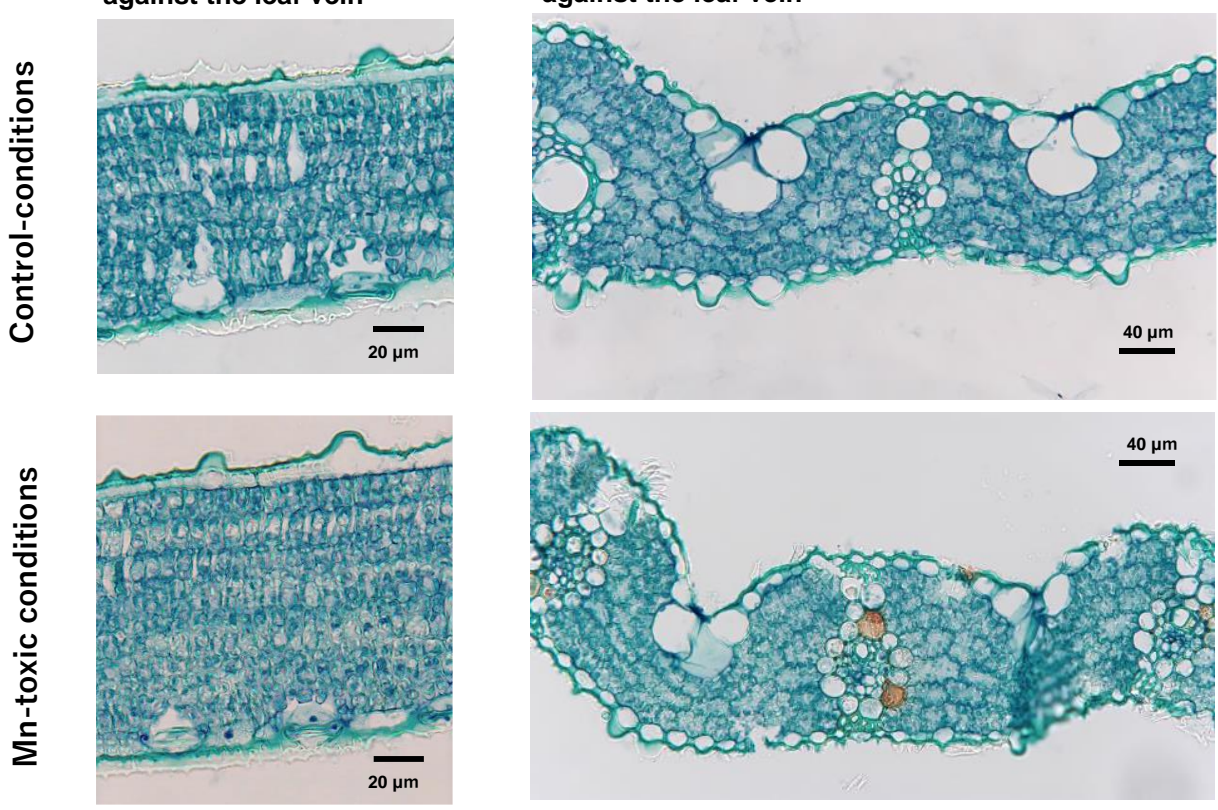

B

C
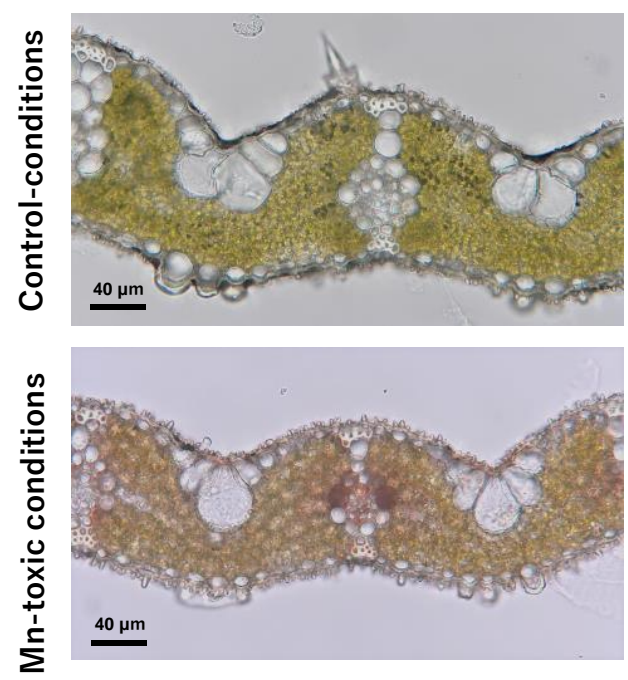

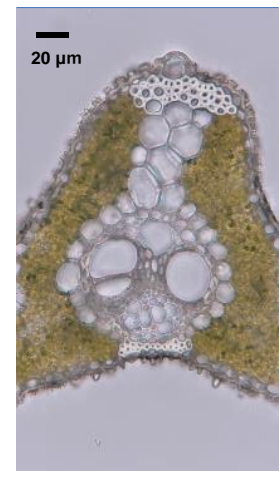

Control-conditions

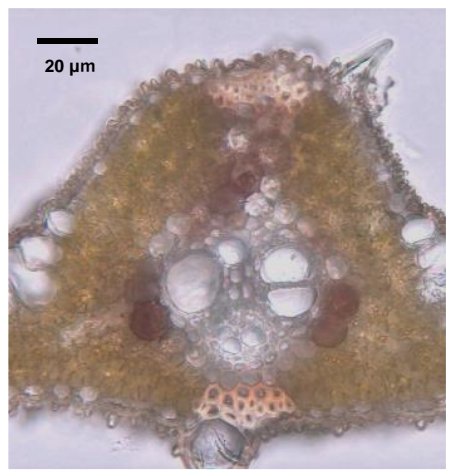

Mn-toxic conditions

\title{
Figure 7
}

Characteristics of the leaf section grown under control and Mn-toxic conditions. (A) Fixed leaf sections sectioned from the horizontal and vertical side against the leaf vein. Fresh leaf sections of the small (B) and large (C) bundles. Black bars show the scales. 
A<smiles>O=C(O)Cc1c[nH]c2ccccc12</smiles>

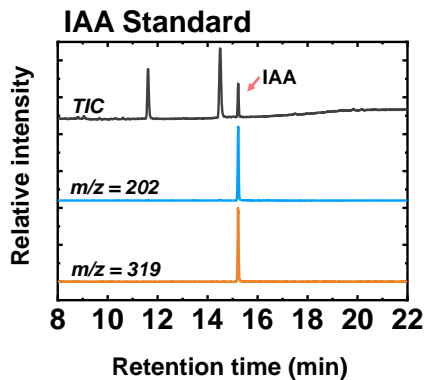

C
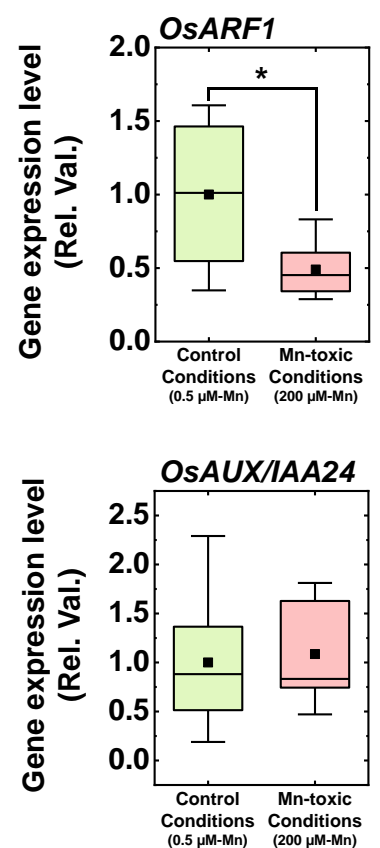

The trimethylsilylated derivative of IAA (IAA-TMS)<smiles>Cn1cc(CC(=O)O[Si](C)(C)C)c2ccccc21</smiles>

Control

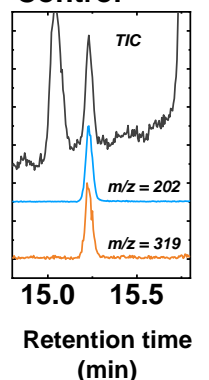<smiles>Cc1cn([Si](C)(C)C)c2ccccc12</smiles>

Mn-toxic

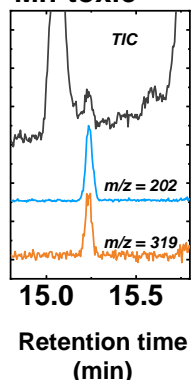

B

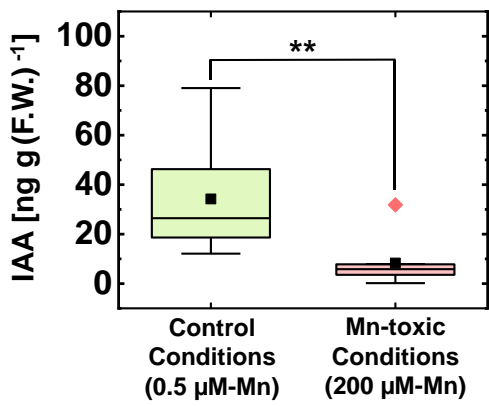

\section{Figure 8}
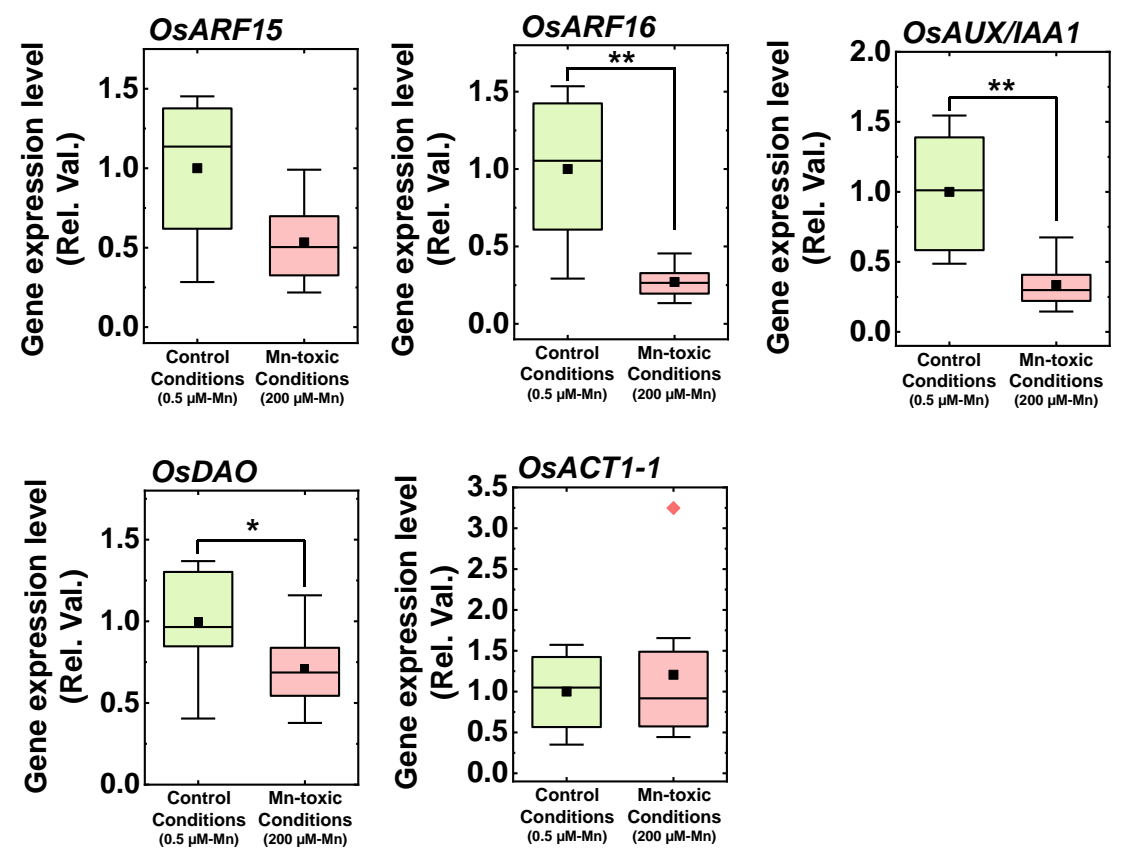

Leaf indole acetic acid (IAA) concentration and gene expression analysis relating to IAA and stomata development. (A) The result of GC-MS analysis targeting IAA, together with the chemical structures of IAA and its derivatives. The total ion chromatography (TIC) and chromatographs of $\mathrm{m} / \mathrm{z}=202$ and $\mathrm{m} / \mathrm{z}=319$ in the standard IAA solution and the leaf extract from plants under control and Mn-toxic conditions are shown. The retention time of the silylated IAA was $15.2 \mathrm{~min}$. (B) The IAA concentrations in the leaf blade $(n=8)$. (D) The results of gene expression analysis involving IAA-responsive gene and stomatal patterning $(n=8)$. The quantified results are expressed on an OSATC1-2 expression basis. Asterisks show significant differences between the control and Mn-toxic conditions $\left({ }^{*}: p<0.05,{ }^{* *}: p<\right.$ 0.01 , Kruskal-Wallis test). 
bioRxiv preprint doi: https://doi.org/10.1101/2021.03.16.435720; this version posted March 18, 2021. The copyright holder for this preprint (which was not certified by peer review) is the author/funder, who has granted bioRxiv a license to display the preprint in perpetuity. It is made available under aCC-BY-ND 4.0 International license.

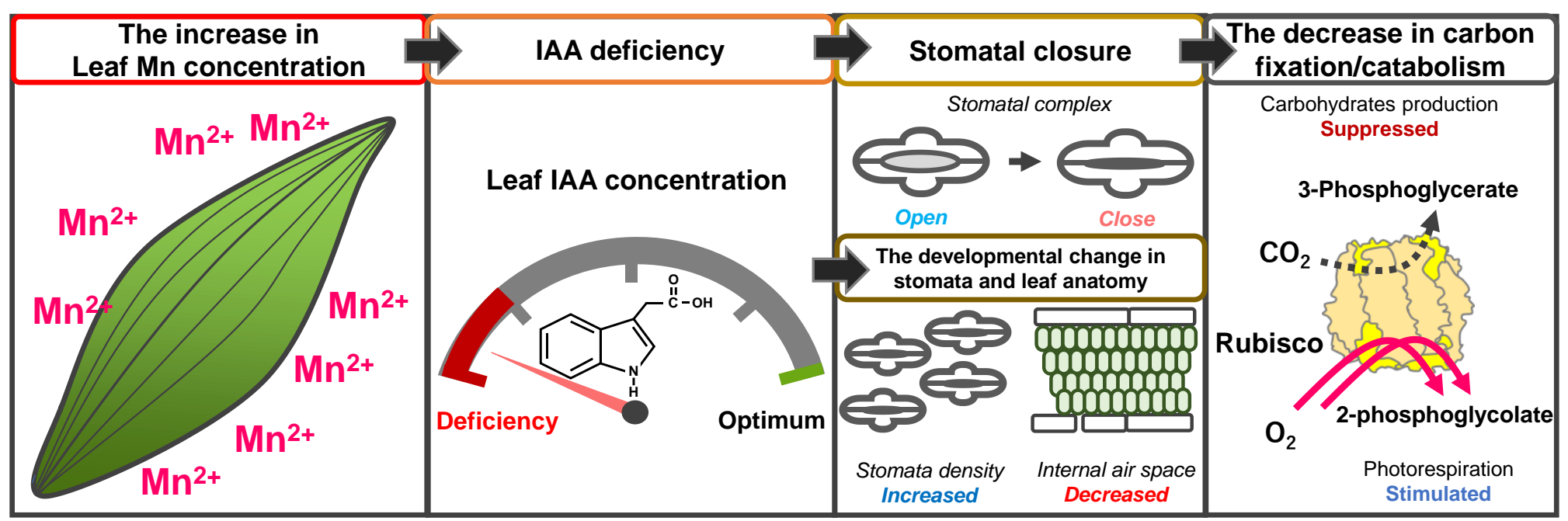

Figure 9

Visual scheme of symplastic $\mathrm{Mn}$ toxicity to suppress $\mathrm{CO}_{2}$ assimilation. When $\mathrm{Mn}$ is excessively accumulated in leaves, the leaf IAA concentration is lowered, which might cause the stimulation of IAA degradation activities under Mn toxicity (Morgan et al., 1996). As a short-term effect, the decrease in IAA concentration affects stomatal opening (Blatt and Thiel, 1994; Klein et al., 2003). Subsequently, as a long-term effect, the auxin-dependent signal transduction involving ARF transcriptional factor is perturbated in the leaves to cause an IAAdeficient phenotype, changing both stomatal and leaf anatomical structures (Le et al., 2014; Zhang et al., 2014). The change in stomatal function and leaf structure severely limits $\mathrm{CO}_{2}$ diffusion to the chloroplasts, and $\mathrm{CO}_{2}$ assimilation by Rubisco is inhibited. In contrast, the photorespiration reaction limits the photosynthetic electron activities to cause ROS production (Wada et al., 2019). The decreased sugar production efficiency in photosynthesis suppresses sugar catabolism. Therefore, growth is inhibited under Mn-toxic conditions. 